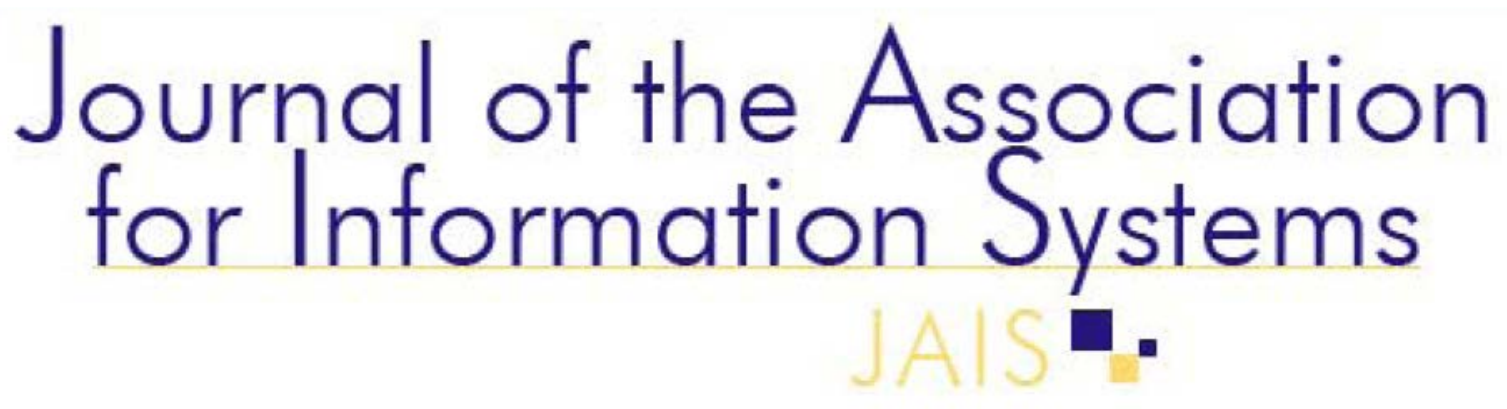

Special lssue

Neurols_Altemative or Complement to Existing Methods? Illustrating the Holistic Effects of Neuroscience and Self-Reported Data in the Context of Technostress Research

\author{
Stefan Tams \\ HEC Montréal \\ stefan.tams@hec.ca \\ Kevin Hill \\ HEC Montréal \\ kevin.hill@hec.ca
}

\author{
Jason Thatcher \\ Clemson University \\ JTHATCH@clemson.edu \\ Varun Grover \\ Clemson University \\ VGROVER@clemson.edu
}

Ana Ortiz de Guinea

HEC Montréal

ana.ortiz-de-guinea@hec.ca

\title{
Abstract
}

Recent research has made a strong case for the importance of NeurolS methods for IS research. It has suggested that NeurolS contributes to an improved explanation and prediction of IS phenomena. Yet, such research is unclear on the source of this improvement; while some studies ind ic ate that NeurolS constitutes an altemative to psychometrics, implying that the two methods assess the same dimension of an underlying IS construct, other studies ind ic ate that NeuroIS constitutes a complement to psychometrics, implying that the two methods assess different dimensions of an IS construct. To clanify the role of NeurolS in IS research and its contribution to IS research, in this study, we examine whether NeurolS and psychometrics/psychological methods constitute altematives or complements. We conduct this examination in the context of technostress, an emerging IS phenomenon to which both methods are relevant. We use the triangulation approach to explore the relationship between physiological and psychological/self-reported data. Using this approach, we argue that both kinds of data tap into different aspects of technostress and that, together, they can yield a more complete or holistic understanding of the impact of technostress on a theoretically-related outcome, rendering them complements. Then, we test this proposition empirically by probing the correlation between a psychological and a physiological measure of technostress in combination with an examination of their incremental validity in explaining performance on a computer-based task. The results show that the physiological stress measure (salivary alpha-amylase) explains and predicts variance in performance on the computer-based task over and above the prediction afforded by the self-reported stress measure. We conclude that NeuroIS is a critical complement to IS research.

Keywords: NeuroIS, Technostress, Correlation, Neurosc ience, Self-reports, Triangulation.

\footnotetext{
* René Riedl was the accepting senior editor. This artic le was submitted on $29^{\text {th }}$ April 2013 and went through three revisions.
} 


\section{NeurolS-Alternative or Complement to Existing Methods? Illustrating the Holistic Effects of Neuroscience and Self-Reported Data in the Context of Technostress Research}

\section{Introduction}

Biology is key to human behavior, which, in turn, is extensively studied in the Social Sciences (Cacioppo, Berntson, Sheridan, \& McClintock, 2000; Wilson, 1977). Consequently, research in the Social Sciences adopted biological or physiological measures as soon as rigorous such measures became available in referent fields (including Neurobiology and Sociobiology) (Cacioppo et al., 2000; Wilson, 1977). Specifically, in the 1970s, physiological measures were adopted by such fields as Anthropology, Psychology, Economics, and Sociology (e.g., Fleising \& Labovitz, 1976; Wilson, 1977). Later, in the 1980s, they were also adopted by organizational researchers, particularly for research on job stress (Cooper, Dewe, \& O’Driscoll, 2001; Eden, 1982; Fried, Rowland, \& Ferris, 1984). Job stress researchers quickly recognized the vast potential of physiological measures to extend understanding of the negative impacts of job stress on employee health and organizational performance. Ultimately, in the late 1990s, job stress researchers concluded that the use of physiological measures to collect physiological data was crucial for research on job stress to advance (Spector, 1999) ${ }^{1}$.

In accordance with these trends in the Social Sciences in general, and in the job stress literature in particular, recent Information Systems (IS) research has emphasized the relevance of physiological measures for examining IS constructs (e.g., Dimoka, Pavlou, \& Davis, 2011; Dimoka et al., 2012; Loos et al., 2010; Riedl, 2009, 2013; Riedl et al., 2010a; vom Brocke, Riedl, \& Léger, 2013). Such research suggests that examining IS constructs using physiological measures can lead to an improved explanation and prediction of IS phenomena (Dimoka et al., 2012; Riedl et al., $2010 a$ ). Consistent with organizational researchers' use of physiological measures for research on job stress, IS researchers have highlighted technostress (i.e., the stress experienced by people as a result of their interactions with technologies (Riedl, 2013)) as a phenomenon that could benefit strongly from the improved explanation and prediction afforded by physiological measures (Riedl, 2013). Technostress has been highlighted as such a phenomenon because only two IS studies on technostress (Riedl, Kindermann, Auinger, \& Javor, 2012, 2013) since the seminal work of Weil and Rosen (1997) have used physiological measures, while the others have exclusively relied on selfreported/psychological measures (e.g., Ayyagari, Grover, \& Purvis, 2011; Ragu-Nathan, Tarafdar, Ragu-Nathan, \& Tu, 2008; Tarafdar, Qiang, Ragu-Nathan, \& Ragu-Nathan, 2007; Tarafdar, Tu, \& Ragu-Nathan, 2010) (also, no IS study on technostress to date has used multiple sources of data). Thus, IS research has called for the use of physiological measures in the study of such IS phenomena as technostress. This call for using physiological measures has led to the emergence of Neurols as a new subfield. Several studies have followed these calls for NeurolS research on technostress and related IS phenomena to improve the explanation and prediction of these phenomena (e.g., Riedl et al., 2012, 2013). For example, Riedl et al. (2012) examined the impact of computer breakdowns on technostress by assessing previously untested elevations in the stress hormone cortisol. Yet, the nature of the contribution physiological measures can make to our understanding of such IS phenomena as technostress remains vague; while NeurolS research suggests that physiological measures can provide improved explanation and prediction of IS phenomena, such research is unclear on the source of this improvement.

On the one hand, a close reading of Neurols research suggests that both physiological and psychological (i.e., self-reported) measures should converge and correlate highly and significantly, indicating that they are "alternative forms of measurement" (Dimoka, 2012, p. 814; Dimoka et al., 2011, 2012). On the other hand, NeurolS research also suggests that physiological measures complement psychological ones by affording "higher levels of explained variance" in IS dependent variables (Riedl et al., 2010a, p. 257) ${ }^{2}$. Whereas the former account indicates that physiological

${ }^{1}$ In this paper, we use the terms data and measures largely as synonyms for ease of readability, although we recognize that data are generally more concrete and constitute the values that measures can take.

2 Consistent with the NeurolS literature, we use the terms alternative and complement in accordance with their basic dictionary meanings. According to Merriam-Webster Online, an alternative is one of two or more things to be chosen (e.g., a physiological measure is chosen instead of a psychological one), whereas a complement is a thing (e.g., a physiological measure) that completes another thing (e.g., a psychological measure) by providing something additional (e.g., it explains additional variance in 
measures should be used either instead of psychological measures due to their presumably better measurement properties or in addition to them for convergent validity assessments (i.e., certainty in the prediction and explanation of a phenomenon), the latter account indicates that physiological measures complete psychological measures by providing additional explanation (i.e., both types of measures together provide for a more complete or holistic understanding of IS phenomena than does either one alone). These accounts are inconsistent since using one measure instead of another or in addition to the other for convergent validity assessments (i.e., the measures are considered alternatives) implies that the two measures assess the same dimension of an underlying IS construct, while using both measures together to obtain a more complete or holistic understanding of an IS phenomenon (i.e., the measures are considered complements) implies that the two measures assess different dimensions of an IS construct (Jick, 1979). In this paper, we help resolve this inconsistency and clarify how NeurolS contributes to improved explanations and predictions of IS phenomena. To this end, we examine whether physiological and psychological measures of IS constructs constitute alternatives or complements. We conduct this examination in the context of technostress; technostress constitutes a useful study context since it is an emerging IS phenomenon to which both kinds of measures are highly relevant (Cacioppo et al., 2000; Cooper et al., 2001; Riedl, 2013).

The paper proceeds as follows. In Section 2, we discuss the triangulation approach (Jick, 1979) as a means to frame a response to our research question. In referring to this approach and drawing from prior research, in Section 3, we develop an argument for why physiological and psychological (selfreported) measures will frequently tap into different aspects of IS constructs, such as the stress experienced in response to technological stressors. As we elaborate, this argument theoretically precludes both kinds of data from being alternative forms of measurement, and it suggests that, together, they can yield a more complete or holistic understanding of IS constructs than either data type can alone. As such, we propose that, together, both kinds of data can provide higher levels of explained variance in IS dependent variables than either one can alone. In Section 4, we examine this idea empirically for the technostress phenomenon by presenting the results of a hierarchical regression analysis, which show that a physiological measure of stress explains and predicts performance on a computer-based task over and above the prediction afforded by a psychological/self-reported measure of stress. Therefore, our paper presumes that NeurolS methods can explain additional variance in IS dependent variables so that these methods can improve our understanding of the effects of such IS phenomena as technostress on relevant outcomes. In Sections 5 and 6, we discuss our findings and offer the concluding argument that NeurolS methods can complement existing IS methods by offering a more complete or holistic understanding of the consequences of such IS phenomena as technostress ${ }^{3}$.

\section{Literature Review on Triangulating Different Sources of Data}

To frame our examination of whether physiological and psychological data constitute alternatives or complements, we use the triangulation approach, which proposes using a combination of different methodologies in the study of the same phenomenon (Denzin, 1989). This combination of different methodologies serves to explain and predict a phenomenon with greater accuracy; that is, it improves the prediction and explanation of the phenomenon (Campbell \& Fiske, 1959; Jick, 1979). To this end, triangulation can take two forms: convergent validation and holistic representation (Jick, 1979) ${ }^{4}$.

IS dependent variables). To be consistent with the NeurolS literature, we use these terms' dictionary meanings and not, for example, the meanings assigned to them by the economic theory of complementarities (e.g., Milgrom \& Roberts, 1995).

3 Note that complementarity can also occur when only different psychological measures are investigated or when only different physiological measures are investigated since different correlation sizes (different levels of convergent validity) can occur within and between each data level. Further, there are many different kinds of data levels, not only psychological and physiological ones (Zuckerman, 1992) (we thank an anonymous reviewer for pointing out this important aspect). However, we chose to examine the relationship between psychological and physiological measures rather than the relationships of different measures within these two data levels or across other kinds of data levels since we deem the examination of the relationship between psychological and physiological measures most pertinent to NeurolS research. This examination was directly based on prior NeurolS research (e.g., Dimoka, 2012; Dimoka et al., 2011, 2012; Riedl et al., 2010a). More specifically, the IS field has had a long tradition of using primarily psychological measures, which implies that the positioning of physiological measures that are new to the IS field in the well-established space of psychometrics is currently unclear. Therefore, the present study is important to clarify the role of NeurolS in the broader IS field.

${ }^{4}$ Discriminant validity is a related and generally equally important term in statistical assessment (Campbell \& Fiske, 1959). Discriminant validity evaluates the extent to which constructs that should be unrelated theoretically are also unrelated in reality (Campbell \& Fiske, 1959). In practical terms, discriminant validity evaluates whether measures of a given construct are unrelated 


\subsection{Convergent Validation}

Convergent validation means that multiple methods should be used in the measurement validation process to help ensure that explained variance is a result of the constructs under investigation rather than the method used. This strategy represents the most popular application of triangulation first introduced by Campbell and Fiske (1959), and it implies that two or more distinct methods are consistent and yield comparable results (Jick, 1979). Multiple measures, if they reach the same conclusions, can provide for a more certain prediction and explanation of a phenomenon (Churchill, 1979; Jick, 1979; Strube \& Newman, 2007). For example, the impacts of a technological stressor on employee well-being could be studied by means of a questionnaire and/or elevations in hormone levels. The theoretical outcome remains employee well-being in either case, but the mode of data collection differs. If the results from both measures converge or agree, the measures are considered valid representations of their underlying construct. By this means, convergent validity can reinforce the certainty and confidence in the nature of the effects of a particular variable on variables with which it is theoretically related as part of a nomological network (Cronbach \& Meehl, 1955).

The convergent validation approach to methodological triangulation involves different measures presumed to assess the same dimension of a construct (Jick, 1979) ${ }^{5}$. For different measures to assess the same dimension of a construct, the variance in them has to overlap; that is, they have to share variance (Campbell \& Fiske, 1959; Churchill, 1979; Rich, Bommer, MacKenzie, Podsakoff, \& Johnson, 1999; Strube \& Newman, 2007). This concept can be illustrated using Venn diagrams that represent shared variance as overlapping areas between two circles. For two measures, Variable 1 and Variable 2, there has to be substantial overlap between them to assess the same dimension of a construct (see Figure 1 left); only then can these measures be representative of the same "thing". Consequently, lack of overlap implies that the measures do not assess the same dimension of a construct (see Figure 1 right) (Strube \& Newman, 2007).
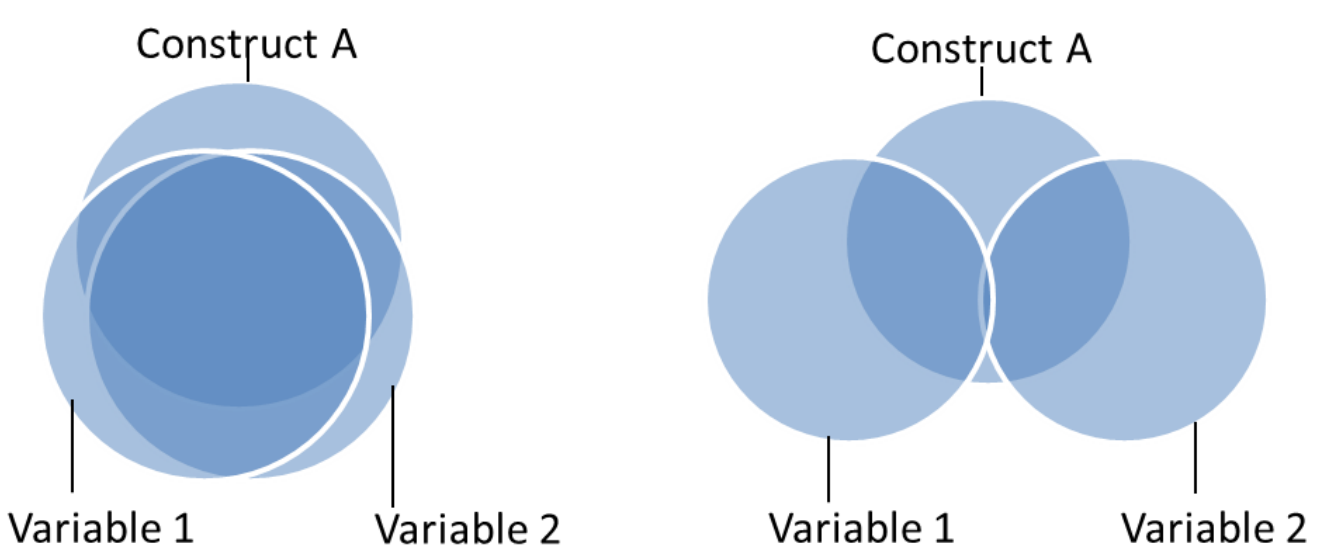

Figure 1. Venn Diagram Illustrating Substantial (Left) and Limited Overlapping Variance (Right)

Convergent validation based on overlapping variance between two measures requires that a significant and large positive correlation exists between them (Jick, 1979; Strube \& Newman, 2007; Tabachnick \& Fidell, 2007). The greater the positive correlation between two measures presumed to represent the same dimension of a construct, the more solid the theoretical position that these measures do, indeed, represent the same dimension of the construct (Cohen, Cohen, West, \& Aiken,

to measures that are not believed to operationalize the construct (Straub, Boudreau, \& Gefen, 2004). However, despite the importance of discriminant validity to statistical assessment, our literature review focuses on convergent validation and holistic representation because those are the concepts most directly related to the question of whether psychological and physiological measures of IS constructs are alternatives or complements. Hence, we focus on convergent validation and holistic representation to frame a response to our research question.

${ }^{5}$ Consistent with Bacharach (1989), we refer to broad mental configurations of a given phenomenon as constructs and to operational configurations derived from constructs as variables (or measures). Hence, constructs are on a more abstract level, while variables are on a more concrete level (Bacharach, 1989). 
2003; Tabachnick and Fidell, 2007). As Churchill (1979, p. 70) notes: "Evidence of the convergent validity of the measure is provided by the extent to which it correlates highly with other methods designed to measure the same construct". Assuming that constructs are assessed with minimal amounts of measurement error, failure to find a significant and large positive correlation contradicts the proposition that the two measures assess the same dimension of an underlying construct. In such situations, where two measures neither correlate at a statistically significant nor at a high level, the measures do not have a common core and do not assess the same dimension of a construct (Churchill, 1979) ${ }^{6}$.

In case of convergence, the results from independent analyses using either measure should explain overlapping variance; as Figure 2 shows, two overlapping independent variables $X 1$ and $X 2$ should be consistent and yield comparable results in their independent predictions of a dependent variable $Y$ (Churchill, 1979; Jick, 1979) 7 .

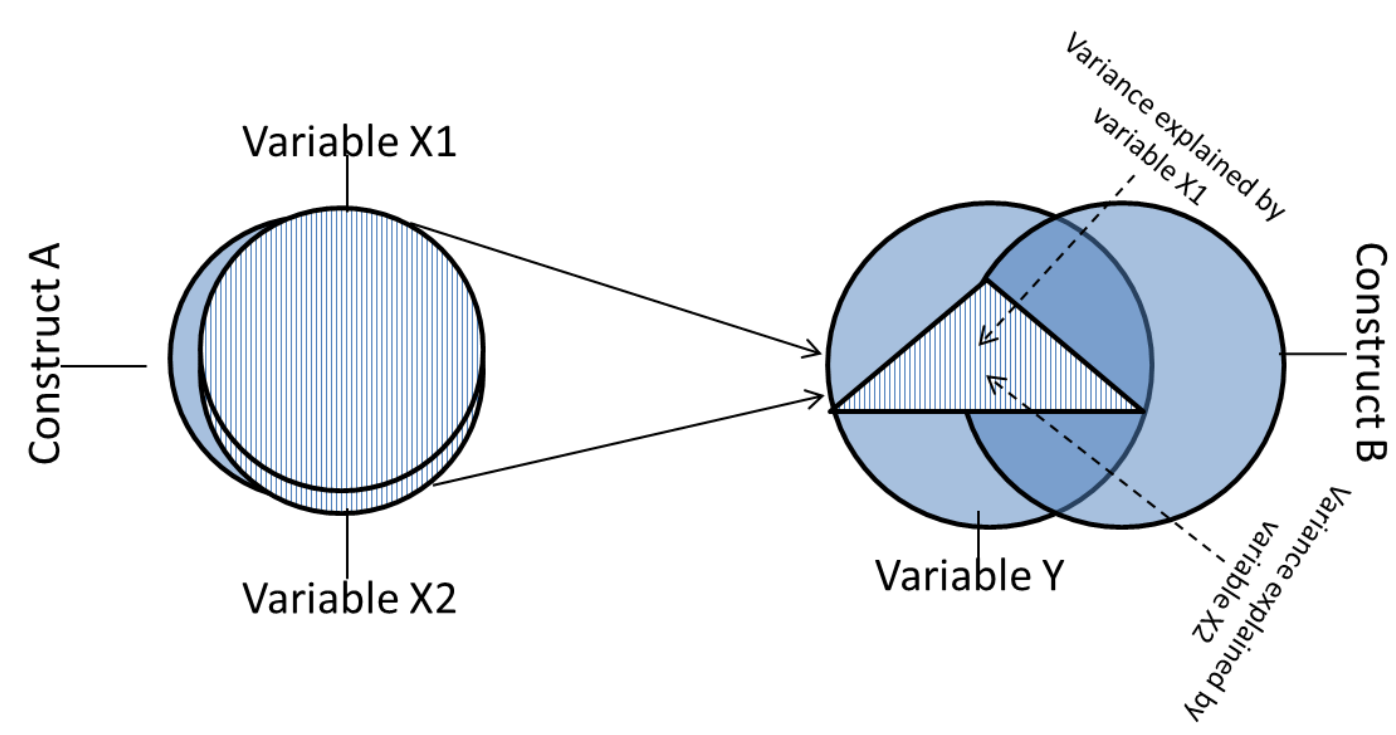

Figure 2. Relational Venn Diagram Illustrating $X 1$ and $X 2$ as Alternatives in the Prediction of $Y$

With respect to the research objective of the present study, the convergent validation approach to methodological triangulation indicates that, in order for physiological and psychological measures of IS constructs to be considered "alternative forms of measurement" (Dimoka, 2012, p. 814), an empirical investigation should provide evidence of a significant and large positive correlation between these two forms of measurement. If physiological and psychological measures of IS constructs do not significantly correlate at high levels, their variance does not overlap. In such situations, they cannot be considered alternative forms of measurement of the same IS construct.

\subsection{Holistic Representation}

As we discuss in Section 2.1, the absence of a significant and large positive correlation between two measures precludes convergent validation. In such situations, the divergence between the measures nevertheless opens up an opportunity for enriching the explanation and prediction of outcomes that are theoretically related to the distinct measures, providing more comprehensive and potentially more complex explanations (Jick, 1979). Such divergence relates to the second approach to

\footnotetext{
${ }^{6}$ We emphasize the following important aspect: while the absence of statistical significance is a strong indicator that measures do not tap the same dimension of a construct (provided that measurement error is not suspected to be the reason), the presence of a significant correlation is merely supportive evidence, not conclusive evidence; significance is not sufficient on its own. Other factors to consider are the size of the correlation and supporting research and theory.

${ }^{7}$ Consistency and comparability in terms of predictive results does not mean that two overlapping independent variables should be used together as predictors in the same statistical model. In fact, such combined use must be avoided; otherwise, problems of multicollinearity can result (Cohen, Cohen, West, \& Aiken, 2003; Tabachnick \& Fidell, 2007).
} 
methodological triangulation referred to as holistic representation, which involves different measures that assess dissimilar but complementary dimensions of a construct (Jick, 1979).

To be clear, the absence of a correlation, by itself, cannot be considered conclusive evidence that two forms of measurement assess complementary dimensions of a given construct. Interpreting complementarity requires additional empirical evidence showing that both forms of measurement explain unique amounts of variance in theoretically related outcomes. That is, divergent measures can be considered complementary if, in addition to the absence of a significant and large positive correlation between them, using them together explains unique variance in an outcome that would have otherwise been neglected (Jick, 1979). More specifically, two divergent measures of the same construct can combine to predict complementary parts of the variance in a dependent variable and, thereby, achieve higher levels of explained variance in the dependent variable than either measure could alone (Cohen et al., 2003; Tabachnick \& Fidell, 2007).

Uncovering unique variance in, for example, IS dependent variables is practical since any one construct operationalization may capture only a part of its underlying construct so that crucial aspects of the effects of an overall construct on theoretically related outcomes may be missed by a single measure of that overall construct (Strube \& Newman, 2007). On this basis, the concept of holistic representation implies that using two divergent measures, which assess two unique aspects of a given construct, together can provide for a more complete or holistic understanding of a phenomenon and of its effects than can be obtained when using either measure alone (Jick, 1979). As a result, a more complete picture and more powerful predictive relationships can be achieved.

With respect to our study, the holistic representation approach to methodological triangulation indicates that, if physiological and psychological measures of IS constructs are divergent (i.e., they do not correlate highly and significantly), these measures could potentially be complementary such that, together, they could yield "higher levels of explained variance" in IS dependent variables (Riedl et al., 2010a, p. 257) than either one could yield alone. Consequently, consistent with Jick (1979), holistic representation is where NeurolS could play a particularly prominent role by producing data and suggesting conclusions to which psychological data obtained from self-reports would be blind. This idea also implies that adding physiological and psychological measures of IS constructs together in an index variable should be avoided; this technique could reduce the richness of the explanation that such measures can produce. Instead, the effects of complementary measures of a construct should be examined concurrently, yet estimated independently (i.e., using hierarchical regression analysis) (Cohen et al., 2003).

\subsection{Summary of the Literature Review and Takeaways for the Present Study}

Overall, the triangulation approach indicates that we have to begin our examination of whether physiological and psychological measures of IS constructs are alternatives or complements by examining the correlation between these measures. Examining the correlation is important since, in order for these measures to be considered alternatives, they have to share variance. This notion implies that both measures have to correlate highly and significantly. Prior research and theory should be consulted to inform our a priori understanding of this correlation before calculating it. After its calculation, if the correlation indicates divergence, we have to examine whether the physiological measure can explain unique variance in a theoretically related outcome above and beyond the variance explained by the psychological measure. This latter examination allows us to determine whether physiological data complete psychological data by affording higher levels of explained variance in IS dependent variables and, thus, whether these data indicate complementarity in the sense of holistic representation. Hierarchical regression analysis can be used for the latter examination (Cohen et al., 2003; Tabachnick \& Fidell, 2007), where the psychological measure is entered in Step 2 of the regression model (after the control variables) and the physiological measure is entered in Step 3. This sequence, in which the measure of primary interest to this study is entered last, allows us to determine whether this measure can, in fact, increase the variance explained in IS dependent variables above and beyond the variance explained by traditional, psychological measures (Cohen et al., 2003; Tabachnick \& Fidell, 2007). More specifically, in case significant incremental variance is explained in Step 3 of the regression model, we can conclude that psychological and physiological measures of IS constructs are complements such that physiological measures complete 
Tams et al. / NeuroIS-Altemative or Complement?

psychological ones by affording higher levels of explained variance in IS dependent variables (e.g., performance on computer-based tasks) (see Table 1).

Table 1. Summary of the Literature Review on the Triangulation of Different Sources of Data

\begin{tabular}{|c|c|c|c|}
\hline \multirow{2}{*}{$\begin{array}{l}\text { Dimension of } \\
\text { comparison }\end{array}$} & \multicolumn{2}{|c|}{ Triangulation approach } & \multirow{2}{*}{ References } \\
\hline & Convergent validation & Holistic representation & \\
\hline $\begin{array}{l}\text { Variance in different } \\
\text { measures }\end{array}$ & Overlapping (shared) & Unique & $\begin{array}{l}\text { Cohen et al. (2003), Jick } \\
\text { (1979), Strube and Newman } \\
(2007), \text { Tabachnick and Fidell } \\
(2007)\end{array}$ \\
\hline $\begin{array}{l}\text { Metaphor for the } \\
\text { relationship between } \\
\text { different measures }\end{array}$ & $\begin{array}{l}\text { Different measures assess } \\
\text { the same dimension of a } \\
\text { construct and can be } \\
\text { interpreted as "apples and } \\
\text { apples" }\end{array}$ & $\begin{array}{l}\text { Different measures assess } \\
\text { dissimilar dimensions of a } \\
\text { construct and can be } \\
\text { interpreted as "apples and } \\
\text { oranges" }\end{array}$ & Jick (1979), Rich et al. (1999) \\
\hline Assessment criteria & $\begin{array}{l}\text { Different measures should } \\
\text { have a significant and large } \\
\text { positive correlation and } \\
\text { should not explain unique } \\
\text { proportions of variance in } \\
\text { theoretically related } \\
\text { outcomes }\end{array}$ & $\begin{array}{l}\text { Absence of a significant, } \\
\text { large positive correlation and } \\
\text { explanation of significant } \\
\text { incremental variance by one } \\
\text { measure over another in a } \\
\text { hierarchical regression model }\end{array}$ & $\begin{array}{l}\text { Campbell and Fiske (1959), } \\
\text { Churchill (1979), Cohen et al. } \\
\text { (2003), Jick (1979), Nunnally } \\
\text { (1978), Rich et al. (1999), } \\
\text { Strube and Newman (2007), } \\
\text { Tabachnick and Fidell (2007) }\end{array}$ \\
\hline $\begin{array}{l}\text { Implications and } \\
\text { takeaways for the } \\
\text { present study }\end{array}$ & $\begin{array}{l}\text { Psychological and } \\
\text { physiological measures are } \\
\text { alternatives }\end{array}$ & $\begin{array}{l}\text { Psychological and } \\
\text { physiological measures are } \\
\text { complements }\end{array}$ & $\begin{array}{l}\text { Cohen et al. (2003), Jick } \\
\text { (1979), Rich et al. (1999), } \\
\text { Tabachnick and Fidell (2007) }\end{array}$ \\
\hline
\end{tabular}

NeurolS research to date has yielded limited insight as to whether psychological and physiological measures of IS constructs can be used for convergent validation or for holistic representation; systematic triangulation has rarely been employed in NeurolS research. More specifically, although NeurolS research is uniquely positioned to explore the triangulation between both kinds of measures, a comprehensive search across more than 40 databases such as Business Source Premier and Academic Search Premier (please see Appendix 1 for the complete list) using the keywords "NeurolS", "triangulation", "instrument validation", and "construct validity" revealed only one published paper. In this paper, Ortiz de Guinea, Titah, and Léger (2013) indicate that a correlation between psychological and physiological measures of IS constructs cannot necessarily be expected. However, the purpose of their study was an assessment of IS construct validity rather than an exploration of the nature of the relationship between both kinds of measures. Hence, research is needed that more systematically assesses the association between both kinds of measures, and Ortiz de Guinea et al. (2013) called for such research. In accordance with this call, in Section 3, we explore whether comparing psychological and physiological measures of IS constructs constitutes a comparison of apples and apples (i.e., the two measures converge) or one of apples and oranges (i.e., the two measures diverge); we conclude that apples and oranges should be expected, which implies that the two kinds of measures may well be complements.

\section{Making the Case for Complements}

The NeuroIS literature often suggests to IS scholars that physiological and psychological measures should converge and correlate at high and significant levels (e.g., Dimoka et al., 2011, 2012). This idea assumes a direct correspondence between both measures such that they assess the same dimension of an underlying IS concept and, thus, could be considered alternatives to each other. Presumably, physiological data are the better alternative since psychological data can suffer from a variety of biases, such as subjectivity, social desirability, and common method bias (Dimoka et al., 2011, 2012; Podsakoff, MacKenzie, Lee, \& Podsakoff, 2003). These biases involve the unwanted, systematic tendency to respond to questionnaire items on a basis other than the item content (Podsakoff et al., 2003). In addition, the subjects' bounded cognitive abilities and observational opportunities may introduce random error in the forms of, for example, recall errors and noncompliance (Bommer, Johnson, \& Rich, 1995; Patterson et al., 1993). 
In contrast to psychological measures, physiological measures are frequently assumed to be free of systematic bias and random error since they are intended to record a behavior or outcome directly, unmediated by cognitive or observational biases (Bommer et al., 1995). Hence, physiological measures are often considered to be more objective in that they are not under the direct control of the research subject's will and consciousness-a sound argument.

Yet, the validity of physiological measures may often be more difficult to determine than that of psychological ones. Physiological measures are often only partly indicative of theoretical constructs since their functions in the organism tend to encompass more than one thing (Schultheiss \& Stanton, 2009). Also, the multiplicity of interactions among the hormonal systems, the brain systems, the body immune system, and the peripheral organs are complex (Fried et al., 1984; Schultheiss \& Stanton, 2009), which makes it difficult to isolate sources of change in these systems and their effects on third variables. For example, increases in certain hormones (e.g., cortisol) in response to computer breakdowns can readily be understood as an indicator of stress (Riedl et al., 2012). However, hormone levels also increase, for instance, after a meal, and they change in response to alcohol consumption and other non-stress related activities (while people often consume alcohol to cope with stress, alcohol by itself is not known to cause stress) (Schultheiss \& Stanton, 2009). The basic threat to validity exposed in this example holds true for many physiological measures, even for such widely used ones as blood pressure (Fried et al., 1984). Hence, physiological data may be biased by related physiological processes. Additionally, physiological data may be biased by related psychological processes. For example, heart rate measures have been shown to be affected by emotional arousal (Lang, Greenwald, Bradley, \& Hamm, 1993; Patterson et al., 1993).

Furthermore, there are elements subject to interpretation in most measures, whether psychological or physiological (Bommer et al., 1995). For example, the interpretation of even the "hardest" physiological measure may itself be open to negotiation, and determining threshold levels for acceptable experiences of stress, trust, or intentions is a subjective matter (Bommer et al., 1995). Besides, physiological activity levels vary between subjects so that researchers must obtain baseline levels of physiological activity and generate results under explicit consideration of this baseline (Wilder, 1958). Concerning external validity, in contrast to psychological measures that can aggregate statements over situations and time, physiological measures are often limited to a distinct situation, which prevents their results from being extrapolated to other situations (Fried et al., 1984). Additionally, physiological measures are often more narrowly focused than psychological ones (Bommer et al., 1995), which implies a potential disadvantage regarding content validity. Moreover, several event-related potentials reported in Beauducel, Debener, Brocke, and Kayser (2000) had reliabilities of close to zero, a finding that casts some doubt on the often assumed superior accuracy of physiological measures. Hence, claims that physiological data are an objective alternative to psychological data may potentially be misleading.

Even if physiological data were indisputably superior to psychological data, the two kinds of data may still be imperfect alternatives. For these kinds of data to be alternatives, physiology and psychology would have to fulfill the same functions for the human being. Yet, physiological data reflect bodily functions and processes, whereas psychological data reflect the state of mind and conscious awareness (Davidson, 2008; Kim, 2000, Robinson, 1983). This contrast implies a principal difference between physiological and psychological data. As a result of this principal difference, physiological and psychological data do not often converge. For example, research suggests that people can already be biologically stressed at an unconscious level-due to such stressors as technologybefore they become consciously aware of their stress (stress generally refers to negative psychological or physiological experiences that push individuals beyond their ability to successfully cope (McEwen, 2006)) (Monat, Lazarus, \& Reevy, 2007; Riedl, 2013). In fact, some have argued that peoples' primary reactions to stressors occur at the unconscious level (i.e., without subjective awareness) because the activities of two main systems responsible for the physiological aspects of stress (i.e., the autonomic nervous system and the hypothalamic-pituitary-adrenal (HPA) axis) operate independently of conscious awareness (Bargh \& Morsella, 2008; Brosschot, 2010; Dijksterhuis \& Nordgren, 2006). Biological stress can even be experienced while sleeping, where it is by definition not consciously experienced (Brosschot, 2010). These notions suggest that physiological and psychological measures are largely non-redundant and dissimilar. 
As a result, conscious stress-methods, such as psychological measures, may be blind to many experiences of stress that can only be explained by physiological measures (Brosschot, Verkuil, \& Thayer, 2010). This conclusion implies that, instead of explaining overlapping variance, physiological measures may explain a unique and large part of the variance in stress above and beyond what is explained by psychological measures (Brosschot, 2010).

In an organizational context, the job stress literature argues that stress involves both psychological and physiological aspects rather than merely one or the other (Cooper et al., 2001). This argument is made because physiological stress is a direct function of environmental stimuli, whereas psychological stress is the result of an interaction between environmental demands and an individual's conscious assessment of those demands. This rationale indicates that physiological and psychological stress are caused by different mechanisms (Cooper et al., 2001). On the basis of these different causal mechanisms, one can presume that physiological and psychological stress are not identical and that they constitute different facets of stress given that-in accordance with such pertinent approaches to the mind-body relationship as anomalous monism-two events are identical if and only if they have the same causes (Kim, 2000). Consistent with this analysis, the job stress literature has shown that conscious perceptions of stress, measured by means of psychological measures or self-reports, often do not correlate with the usually unconscious physiological reactions to organizational stressors (Riedl, 2013, citing van Eck, Berkhof, Nicolson, \& Sulon, 1996; Vedhara, Hyde, Gilchrist, Tytherleigh, \& Plummer, 2000; Vedhara et al., 2003). Further, there is some initial evidence that psychological and physiological measures of technology-induced stress neither correlate highly nor significantly with each other (Riedl, 2013). For instance, using 14 subjects, Korunka, Huemer, Litschauer, Karetta, and Kafka-Lützcow (1996) examined the effects of working with new technologies on elevations of stress hormone levels and stress perceptions. They failed to detect significant relationships between both kinds of measures across a variety of analyses using different hormones and perceptual measures of stress. While Korunka et al.'s (1996) findings may have been the result of a rather small sample size, they offer some initial indication that psychological and physiological measures of IS constructs may not correlate at high and significant levels.

Overall, theory and empirical research lead us to propose that psychological and physiological measures of an IS construct may not assess the same dimension of the construct and should, hence, perhaps not be treated as alternatives (Lev-ari, Maimon, \& Yaal-Hahoshen, 2006). This proposition implies-based on the triangulation approach-that psychological and physiological measures of IS constructs should neither correlate highly nor significantly and that they each may explain unique proportions of variance in theoretically related outcome variables.

\section{Illustrative Study}

To test the idea that psychological and physiological measures of an IS construct may not assess the same dimension of the construct, implying that they should neither correlate highly nor significantly ${ }^{8}$, we conducted a laboratory experiment in the context of technostress. We selected technostress as the research context due to its theoretical and practical significance; technostress is pertinent to both human psychology and physiology (Riedl, 2013), and it has been shown to have a variety of negative organizational consequences such as reduced performance on computer-based tasks (Ayyagari et al., 2011; Cooper et al., 2001; Tarafdar et al., 2010). Further, technostress is an emerging phenomenon that could strongly benefit from the use of physiological measures. A recent review paper (Riedl, 2013) that examined the potential of physiological measures to advance research on technostress concluded-consistent with the job stress literature-that "biological measures (e.g., stress hormone levels, cardiovascular activity) are crucial predictors of human health, making them an indispensable complement to self-reports on stress perceptions" (Riedl, 2013, p. 18); however, IS research on technostress has relied almost exclusively on self-reported/psychological measures (e.g., Ayyagari et al., 2011; Ragu-Nathan et al., 2008; Tarafdar et al., 2007; Tarafdar et al., 2010) (for exceptions, please see Riedl et al., 2012, 2013).

\footnotetext{
${ }^{8}$ Note that-since significance depends on sample size-even measures indicating rather different constructs could have small but highly significant correlations when the sample size is large.
} 
We conducted our experiment using student subjects since using students reduced the number of confounding variables and increased the internal validity of our results (Appan \& Browne, 2012; Polites \& Karahanna, 2012). We focused on internal validity rather than external validity with this research because we were concerned with issues related to scientific measurement rather than workplace design (Mook, 1983). Consistent with other experimental IS research (e.g., Dennis \& Kinney, 1998; Suh \& Lee, 2005; Tam \& Ho, 2006), 67 percent of the study participants were male, the average age was 21 years, and the subjects received monetary compensation for their participation (US\$15). Furthermore, participation was strictly voluntary, and the participants provided written consent prior to participation. We precluded prospective candidates with diagnosed elevated stress levels, known heart conditions, or increased blood pressure from participating in the study.

\subsection{Experimental Task}

Consistent with recent experimental research in IS (e.g., Dabbish \& Kraut, 2008; Liu et al., 2013; McFarlane, 2002), Psychology (e.g., Baker-Ward \& Ornstein, 1988; Schumann-Hengsteler, 1996; Washburn, Gulledge, James, \& Rymbaugh, 2007), and Bio-Behavioral Studies (Granger et al., 2006; Granger, Kivlighan, el-Sheikh, Gordis, \& Stroud, 2007), the experiment employed a game-like computer-based task. Game-like computer-based tasks, such as the online browser game Memory/Concentration, offer many benefits for experimental research (Washburn, 2003; Washburn \& Gulledge, 1995). These tasks are intrinsically motivating and, thus, elicit motivated performance. As such, they are particularly useful for research on technostress and for the present study since stress is a function of motivated performance (Cooper et al., 2001). Further, these tasks provide continuity and context for responding (Washburn, 2003), and the platform-based technologies on which they are generally performed are becoming increasingly important in the information economy (Ceccagnoli, Forman, Huang, \& Wu, 2012).

The task we employed for this study was an adaptation of the memory game Memory/Concentration, which required the subjects to find matching pairs of symbols in a matrix by flipping computergenerated cards. In the process, the subjects had to memorize the symbols they had seen and where the symbols were located in the matrix (please see Schumann-Hengsteler (1996) for a detailed description of this task). The symbols required the subjects to perform arithmetic: one card specified an integer, and the matching card specified a multiplication yielding this integer. For instance, a matching pair consisted of one card with the symbol " 39 " and another with the symbol " 13 * 3 ". The cards were drawn at random, and we incentivized good task performance to yield motivated performance above and beyond the motivating nature of the task. More specifically, we used two incentive mechanisms: a performance-based lottery and a participant ranking. The lottery featured three valuable prizes (e.g., the Nintendo Wii), whose drawing depended on subject performance in the task such that higher performance yielded a greater likelihood to win a prize (in terms of a larger number of lottery tickets). For the ranking, the subjects provided counterfeit names (e.g., "Mike85"), which we then used to compile a performance-based ranking that was sent to all participants once the study was completed. This ranking increased the competitive nature of the task and made participation more meaningful (i.e., participation became meaningful above and beyond the intrinsically motivating nature of the task). Overall, the task was both complex and competitive.

Prior to the experimental trial, the participants went through a practice trial of the task. The duration of the experimental procedure was 30 minutes, and the participants received no detailed, personalized performance feedback in accordance with the requirements of the institutional review board.

\subsection{Physiological and Psychological Measures of Stress}

While the subjects were working on the computer-based task, stress was induced through instant messages that appeared on the computer display. The messages came in two frequencies: low for the control group (every 90 seconds) and high for the experimental group (every 15 seconds) (following Cook and Campbell (1979), the subjects were randomly assigned to the two groups). Manipulation checks confirmed the validity of the frequency manipulation. The messages were meaningfully related to the task to attract participant attention; yet, they were irrelevant for completing it so as not to confound task performance effects. More specifically, the messages contained additive equations in the form of " $64+64=128$ ". The messages disrupted subjects' thinking processes to 
hinder effective goal attainment and subsequently induce stress (Tarafdar et al., 2010). Consistent with prior research (e.g., Theeuwes, 1991), the subjects were instructed to ignore the interruptions in order to prevent confounding effects due to individual differences in reactions to instant messages.

We measured stress physiologically via the salivary stress enzyme $\alpha$-amylase before and after the task (following a pre-post design allowed us to capture true physiological stress responses and to infer that those physiological responses were task-related (Cook \& Campbell, 1979)). Salivary aamylase (sAA) is a marker of the sympathetic nervous system component of the psychobiology of stress that reflects changes in the stress hormone adrenalin (Granger et al., 2007). As such, sAA is a cutting-edge measure of stress in bio-behavioral research (Granger et al., 2007), although it can be sensitive to noise (Nater \& Rohleder, 2009). More specifically, much like cortisol, sAA is sensitive to alcohol, food, dairy, and caffeine consumption (Granger et al., 2007; Salimetrics, 2011), which means that these aspects need to be controlled for (please see Riedl, 2013, for a more detailed discussion of the characteristics of hormones as indicators of stress and of the endocrinological system).

sAA is officially classified as family 13 of the glycosyl hydrolases, and it reacts to both physical and psychological stressors (Granger et al., 2007). The latter characteristic renders it useful for research on technostress since technostress can arise from both psychological and physiological stressors (e.g., Ayyagari et al., 2011; Riedl et al., 2012; Riedl, 2013). Additionally, sAA can be collected noninvasively (Granger et al., 2007), which makes it useful for research on technostress since its collection, by itself, is not very likely to create an alternative explanation for stress effects (Riedl, 2013). Further, prior research indicates that adrenaline is a particularly relevant hormone in the context of computer-related work; for example, adrenaline is more relevant in this context than is cortisol (Korunka et al., 1996). An added advantage of sAA is that it peaks much faster (usually within 5 minutes poststressor) than does cortisol (usually within 20 minutes) (Granger et al., 2007), which means that its collection can entail a lower logistical burden than that of cortisol. We administered the sAA measure directly before the task and three minutes post-task by instructing the subjects to open a tube and insert a cotton-like oral swab into their mouths for two minutes (Salimetrics, 2011; Neupert, Miller, \& Lachman, 2006).

Moreover, we assessed stress psychologically directly following the task. This assessment used an existing stress measure; we adapted a five-item scale from Moore (2000) and Schaufeli, Leiter, and Kalimo (1995). In line with much prior stress-related experimental research (e.g., Kirschbaum, Klauer, Filipp, \& Hellhammer, 1995; Plante \& Ford, 2000), this scale asked the subjects how much stress they experienced in response to the task they had just performed. As such, this measure directly captured perceived stress in response to the experimental task, which implies that this measure was directly related to the task. A sample item is "I felt strain due to the task demands" (see Appendix 2). Although we adapted an existing scale, we subjected the scale to a pilot-test in a sample of 24 respondents, and we found evidence of good measurement properties (e.g., alpha exceeded 0.80).

Concerning the main experiment, the results from a power analysis using G*Power 3.1 (Faul, Erdfelder, Buchner, \& Lang, 2009) and specifying a population effect size of 0.5 revealed that a sample size of 29 subjects was adequate for a desired power level of 0.80 and a two-tailed test. In our main experiment, we collected data from 64 participants. A direct comparison of the experimental and control groups in terms of stress differences revealed no effect of the experimental manipulation on either measure of stress for the student participants (also see Table 2) ${ }^{9}$.

An independent samples t-test was conducted that showed no significant difference between the two groups for either psychological stress $(t=.615, p>0.05)$ or physiological stress $(t=.728, p>0.05)$. We explore the potential reasons for this result in the limitations section (e.g., the effect of interruptions on stress may be indirect or may depend on relevant individual differences, such as age). 
Tams et al. / Neurols-Altemative or Complement?

Table 2. Means and Std. Errors by Condition

\begin{tabular}{|c|c|c|c|}
\hline Condition & Measurement occasion & Mean & Std. error \\
\hline \multirow{3}{*}{ Control group } & Pre-task SAA & 25.98 & 3.31 \\
\cline { 2 - 4 } & Post-task SAA & 27.72 & 4.34 \\
\cline { 2 - 4 } & Perceived Stress (Post-task) & 2.33 & 0.17 \\
\hline \multirow{2}{*}{ Experimental group } & Pre-task SAA & 26.10 & 3.53 \\
\cline { 2 - 4 } & Post-task sAA & 32.49 & 4.91 \\
\cline { 2 - 4 } & Perceived Stress (Post-task) & 2.18 & 0.16 \\
\hline
\end{tabular}

\subsection{Results with Respect to Convergent Validation}

To appropriately compare the measures, we standardized them using Zscores before conducting the analyses (Cohen et al., 2003). This standardization enabled us to compare the measures despite the different distributions that usually accompany different kinds of measures (Cohen et al., 2003). To triangulate across pertinent data-analytic techniques, we conducted two kinds of correlation analyses. The first analysis correlated the difference score between pre- and post-task physiological stress (SAA) with (post-task) psychological stress, and the second analysis calculated the partial correlation between post-task SAA and (post-task) psychological stress while controlling for pre-task sAA. The former technique was consistent with research in Biostatistics (e.g., Farrar, LaMoreaux, Werth, \& Poole, 2001) and appropriate since we had standardized the data. Yet, the latter technique was particularly rigorous since it produced an adjusted estimate of the correlation, one that was the most precise and the least biased (Cohen et al., 2003). It enabled a direct comparison of both post-task measures. In this comparison, the physiological measure was task-related because we controlled for pre-task SAA, and the psychological measure was task-related because subjects were asked to rate their stress perceptions in response to the task.

Independent of the kind of correlation analysis performed, the results from the main experiment confirmed our proclamation. As regards the bivariate correlation between a) the difference score between pre and post-task SAA and b) (post-task) psychological stress, the two measures of stress shared no variance (shared variance $=0.000196)$. Further, the correlation $(r=0.014$, attenuationcorrected $r=0.016$ ) was non-significant ( $p>0.05$ ), a finding that one would hardly expect if one assumed the two measures evaluate the same dimension of an underlying IS concept (i.e., the same form of technostress). We obtained a similar finding for the partial correlation between post-task sAA and (post-task) psychological stress while controlling for pre-task sAA. Again, the two measures of stress shared no variance (shared variance $=0.000169)$, and the correlation $(r=0.013$, attenuationcorrected $r=0.015)$ was non-significant $(p>0.05)^{10}$.

Our careful research design ensured that these findings were unlikely to be artifacts of bad measurement properties; we ensured that the physiological data were not distorted by such noise as alcohol, food, dairy, or caffeine consumption. To this end, we instructed the subjects before their arrival to the lab not to take any of these substances, and we asked them after their arrival whether they had taken any of these substances (Granger et al., 2007; Salimetrics, 2011). We excluded subjects who had taken any of these substances from the study. Furthermore, we ensured that the self-reported measure had good measurement properties $(\alpha=.85)$. An important strength of the study was that we assessed physiological and psychological stress using fundamentally different methods and, therefore, effectively addressed common method bias that often represents a threat to internal validity. Social desirability bias and fundamental attribution errors were unlikely to occur since we did not ask participants to rate their task performance or other sensitive subjects. Further, we emphasized such pertinent procedural remedies as the protection of respondent anonymity to obtain unbiased and

${ }^{10}$ We calculated the attenuation-corrected correlation using internal consistency reliabilities of 0.85 for the psychological and physiological measures. Concerning the psychological measure, a was 0.85 . For the physiological measure, calculating Cronbach's alpha using the two measures of SAA (pre and post task) yielded an estimated reliability of this measure of 0.85 also. We thank an anonymous reviewer for pointing out the importance of always calculating reliabilities for all measures. 
reliable self-reported data (Podsakoff et al., 2003). Hence, we conclude, on the basis of our results, that the physiological and psychological measures did not assess the same facet of technostress.

This analysis is consistent with research in other fields, which has frequently discovered low correlations between psychological and physiological measures (Rich et al., 1999; van Eck et al., 1996; Vedhara et al., 2003). Thus, expecting high correlations and convergence between physiological and psychological measures of IS constructs and treating them as alternatives may imply trading "apples for oranges" (Rich et al., 1999, p. 42). However, as indicated by the triangulation approach, divergence is an opportunity for enriching the explanation and prediction of a phenomenon since it allows one to generate more complex explanations (Jick, 1979). In effect, physiological and psychological measures may be complementary such that, together, they might yield higher levels of explained variance in IS dependent variables. This idea suggests that one measure alone may yield an incomplete picture of an IS phenomenon, a notion that we examine empirically for the technostress phenomenon in Section 4.4.

\subsection{Results with Respect to Holistic Representation Based on a Conceptual Extension}

As the triangulation approach indicates, if two measures of a construct diverge instead of convergesuggesting that each measure captures unique variance-then these measures may be complementary such that, together, they can explain more variance in a dependent variable than either one can alone (Jick, 1979). This proposition is not only statistically sound, but it also has intuitive appeal (e.g., in the context of technology usage, largely due to the complexity of the technology use process) (Ortiz de Guinea \& Webster, 2013). More specifically, consistent with Katona (1976), we do not doubt that it is possible to demonstrate the influence of brain activation patterns on use behavior beyond that of mere perceived usefulness or perceived ease of use. Likewise, we do not doubt that it is possible to demonstrate the impact of perceived usefulness or perceived ease of use on usage beyond that of mere brain activation patterns. Thus, if we described thinking about technology merely as a matter of potentially biased self-reported perceptions, we may fail to understand an important part of the technology use phenomenon (i.e., the unconscious part) (Loucks, 1941). Similarly, if we described thinking about technology merely as a matter of muscle contractions, we may miss an important part of the picture vis-à-vis technology use (i.e., the conscious part). Yet, these two measures may be complementary such that, together, they afford higher levels of explained variance in technology use. This notion is consistent with research on the mind-body relationship, which indicates that people can neither exist with a body nor with a mind alone; both mind and body are necessary for a person to survive (Lev-ari et al., 2006; Loucks, 1941). Further, this notion is consistent with stress research, which indicates that using both psychological and physiological measures together entails that "a greater picture can be obtained and more powerful predictive relationships achieved" (Travers \& Cooper, 1994, p. 145).

To test the idea of complementarity of psychological and physiological measures of IS constructs in a manner consistent with the triangulation approach, we conducted a hierarchical regression analysis on the data from the previously specified experiment. More specifically, consistent with the stress research literature (Cooper et al., 2001), we regressed performance on the computer-based task in terms of task efficiency (number of matching pairs uncovered relative to the number of cards flipped) on both measures of stress. We selected performance on the computer-based task as our dependent variable since both the job stress and technostress literatures have argued that stress, whether physiological or psychological, has negative consequences for task performance (Beehr, 1995; Folkman \& Lazarus, 1984; Ragu-Nathan et al., 2008; Tarafdar et al., 2007; Van Harrison, Caplan, \& French, 1982) ${ }^{11}$. As people experience stress, they devote a large amount of their limited energy to coping with this negative sensation rather than working and, thus, perform at a lower level (Lord \& Kanfer, 2002). Stress may also result in reduced performance since people often attempt to escape from situations perceived as unfavorable, such as stressful ones (Chang, Rosen, \& Levy, 2009; Lang, Thomas, Bliese, \& Adler, 2007). Consistent with this analysis, two recent technostress studies

\footnotetext{
${ }^{11}$ Note that performance measures can also be regarded as psychometric ones; performance measures have been considered psychometric measures since the beginning of behavioral research (e.g., Spearman, 1904). We thank an anonymous reviewer for pointing this important aspect out to us.
} 
(Chilton, Hardgrave, \& Armstrong, 2005; Tarafdar et al., 2007) found that technostress may reduce performance on computer-based tasks ${ }^{12}$.

Consistent with prior research on technostress, we controlled for gender and education (e.g., RaguNathan et al., 2008). Since we employed a computer-based task using arithmetic, we also controlled for computer experience, computer self-efficacy, arithmetic experience, arithmetic self-efficacy, and arithmetic ability. We also controlled for experimental condition to account for any potential differences between the experimental and control groups in the dependent variable, and we controlled for pre-task SAA. Following procedures recommended by Cohen et al. (2003) and Tabachnick and Fidell (2007), we entered the control variables in Step 1 of the regression model, the psychological measure of stress in Step 2, and the physiological measure of stress in Step 3. This sequence, in which we entered the physiological measure into the regression model after the psychological one, allowed us to examine whether the physiological measure explained additional variance in performance over and above the variance explained by the psychological measure, and it allowed us to examine how much additional variance the physiological measure explained (Tabachnick \& Fidell, 2007) ${ }^{13}$.

The results reveal that the psychological measure explained 6 percent (6\% adjusted) of the variance in performance $(\beta=-.269, p<.05)$ and that the physiological measure explained an additional 6 percent $(6 \%$ adjusted) over and above the variance explained in Step $2(\beta=-.416, p<.05)$. The psychological effect remained significant in Step 3; like the physiological effect, it was independent. Overall, after Step 3, with all independent variables in the equation, $R^{2}=.35$ (adjusted $\left.R^{2}=.21\right), F(11$, $49)=2.408, p<.05$. For the increments, after Step 1 , with the control variables in the equation, $R^{2}$ $=.23$ (adjusted $\left.\mathrm{R}^{2}=.09\right)$, Finc $(9,51)=1.683, \mathrm{p}>.05$. After Step 2, with psychological stress added to the prediction of performance, $R^{2}=.29$ (adjusted $R^{2}=.15$ ), Finc $(1,50)=4.318, p<.05$. Hence, the addition of psychological stress to the equation resulted in a significant increment in $\mathrm{R}^{2}$. After Step 3 , with physiological stress added to the prediction of performance, $R^{2}=.35$ (adjusted $\left.R^{2}=.21\right)$, Finc $(1$, $49)=4.574, p<.05$. Thus, adding physiological stress to the equation resulted in a significant increment in $\mathrm{R}^{2}$ (Table 3). These results indicate that, together, psychological and physiological data yielded a more complete or holistic understanding of performance on a computer-based task than either data type did alone, which implies that these kinds of data were complementary so that, together, they afforded higher levels of explained variance in performance. The physiological measure explained 6 percent of additional variance in performance, variance to which the psychological measure was blind.

Table 3. Hierarchical Regression Model: Variance Explained in Each Step

\begin{tabular}{|l|c|c|c|c|}
\hline Regression step & $\boldsymbol{\beta}$ & $\mathbf{F}$ change & $\mathbf{s r}^{\mathbf{2}}$ & sr $^{2}$ adjusted \\
\hline Step 1 (Control variables) & & 1.683 & .23 & .09 \\
\hline Step 2 (Psychological Stress) & -.269 & $4.318^{\star}$ & $.06^{\star}$ & .06 \\
\hline Step 3 (Physiological Stress) & -.416 & $4.574^{\star}$ & $.06^{\star}$ & .06 \\
\hline $\mathrm{R}^{2}=.35$; Adjusted $\mathrm{R}^{2}=.21 ;{ }^{*} \mathrm{p}<.05$. & \multicolumn{4}{|l}{} \\
\hline
\end{tabular}

${ }^{12}$ On the grounds of parsimony, we focus on the performance decrements resulting from experiences of distress associated with high arousal, although stress could also have a curvilinear relationship with performance. Specifically, although some (e.g., Beehr, 1995) hold that arousal may predict performance through an inverted, U-shaped curve, others found strong support for a linear relationship (Chang et al., 2009; Chilton et al., 2005; Lang et al., 2007; Tarafdar et al., 2007). In this study, post-hoc analyses examining the curvilinear nature of the relationship between stress and performance supported the latter. Neither psychological stress nor physiological stress had a quadratic relationship with performance.

${ }^{13}$ The post-task measure of physiological stress (SAA) served as the substantive variable of physiological stress in the analysis. We included pre-task SAA in the analysis as a control variable to account for baseline stress values and to enable the comparison of individual pre-post differences. We deemed this approach more appropriate than calculating and including the difference score between post and pre-task SAA since the use of a pre-task measure as an additional control variable is generally regarded as more rigorous than the calculation of difference scores (i.e., using the pre-task measure as a control variable is more effective in countering possible regression to the mean and related problems than is the calculation of a difference score) (Cohen et al., 2003). 


\section{Discussion}

This study yielded initial evidence in the context of technostress that physiological measures are complements to psychological ones rather than alternatives; the triangulation of physiological measures with psychological ones can result in a more holistic representation of IS constructs. This finding suggests that physiological measures are a vital complement to existing methods since they can improve the prediction of outcomes related to such IS phenomena as technostress above and beyond that afforded by psychological measures. We found that the physiological measure of stress explained an additional 6 percent of the variance in performance on the computer-based task over and above the variance explained by the psychological measure. With the physiological measure included in the analysis, the total variance explained in performance increased from 29 percent to 35 percent (adjusted from 15\% to 21\%). Hence, our results were consistent with Riedl et al.'s (2010a, p. 257) postulate that NeurolS methods yield "higher levels of explained variance" in IS dependent variables, which suggests that NeurolS can help IS research obtain a more complete or holistic understanding of the effects of such IS phenomena as technostress on relevant outcomes.

In accordance with the triangulation approach (Campbell \& Fiske, 1959; Jick et al., 1979), we first examined whether our psychological and physiological measures assessed the same dimension of technostress. Since these measures shared no variance, we concluded that they were unlikely to assess the same dimension of technostress (see Figure 3), suggesting that they did not constitute alternative forms of measurement in the sense that physiological data could be used either instead of psychological data due to their presumably better measurement properties or in addition to them for convergent validity assessments ${ }^{14}$. Next, we found that the physiological measure explained significant incremental variance in performance, a theoretically-related outcome variable. Consistent with approaches to the mind-body relationship (e.g., Kim, 2000), with research on neurobiology (e.g., Brosschot et al., 2010), and with research on technostress (e.g., Riedl, 2013), the combined evidence of (1) the lack of a significant positive correlation and (2) the explanation of significant incremental variance in performance led us to conclude that the physiological measure captured the unconscious component of technostress while the psychological measure captured the conscious component. Hence, the psychological measure, which is focused on the experience of stress of which the subjects were consciously aware and of which they could give an introspective account in self-reports, may have been blind to unconscious experiences of technostress that could only be explained by a physiological measure, such as SAA (Brosschot et al., 2010). Overall, by examining both unconscious and conscious aspects of technostress in this study, we found evidence of holistic representation effects; we represented technostress holistically so that physiological data could complete psychological data in the prediction of task performance (see Figure 4 showing that the two divergent measures of technostress used in this study combined to predict complementary parts of the variance in task performance).

\footnotetext{
${ }^{14}$ Cacioppo, Tassinary, and Berntson (2007) differentiate among four main psychophysiological relationships: psychophysiological outcomes, markers, concomitants, and invariants. According to this classification, the physiological measure sAA used in our study likely constituted a marker variable since it ranked low on sensitivity (i.e., the likelihood that a physiological response correlates with a psychological variable). This conclusion is also consistent with Granger et al. (2007), van Eck et al. (1996), and Vedhara et al. $(2000,2003)$, and it implies that sAA can be used to draw inferences about various psychological and behavioral manifestations of IS phenomena (Cacioppo et al., 2007).
} 


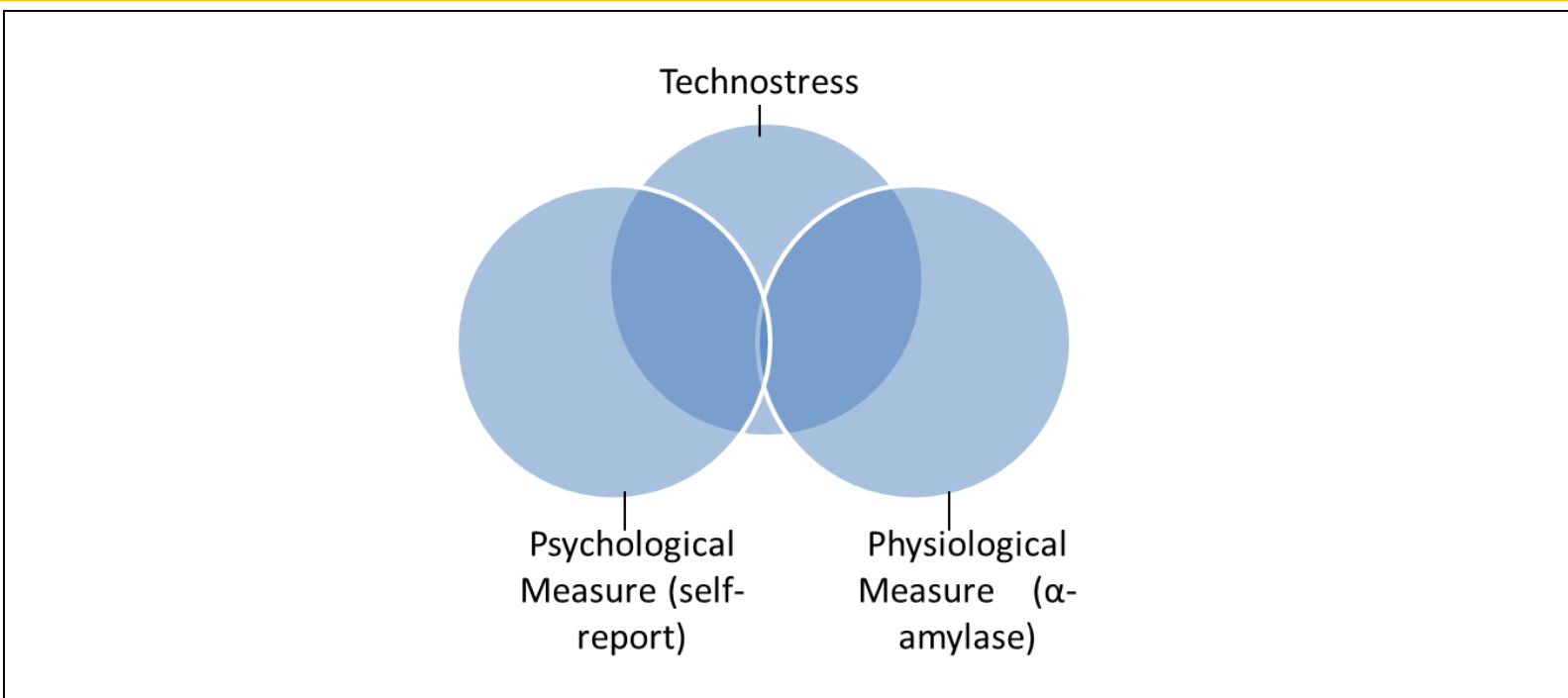

\section{Figure 3. Illustration of the Relationship Between Our Study Variables}

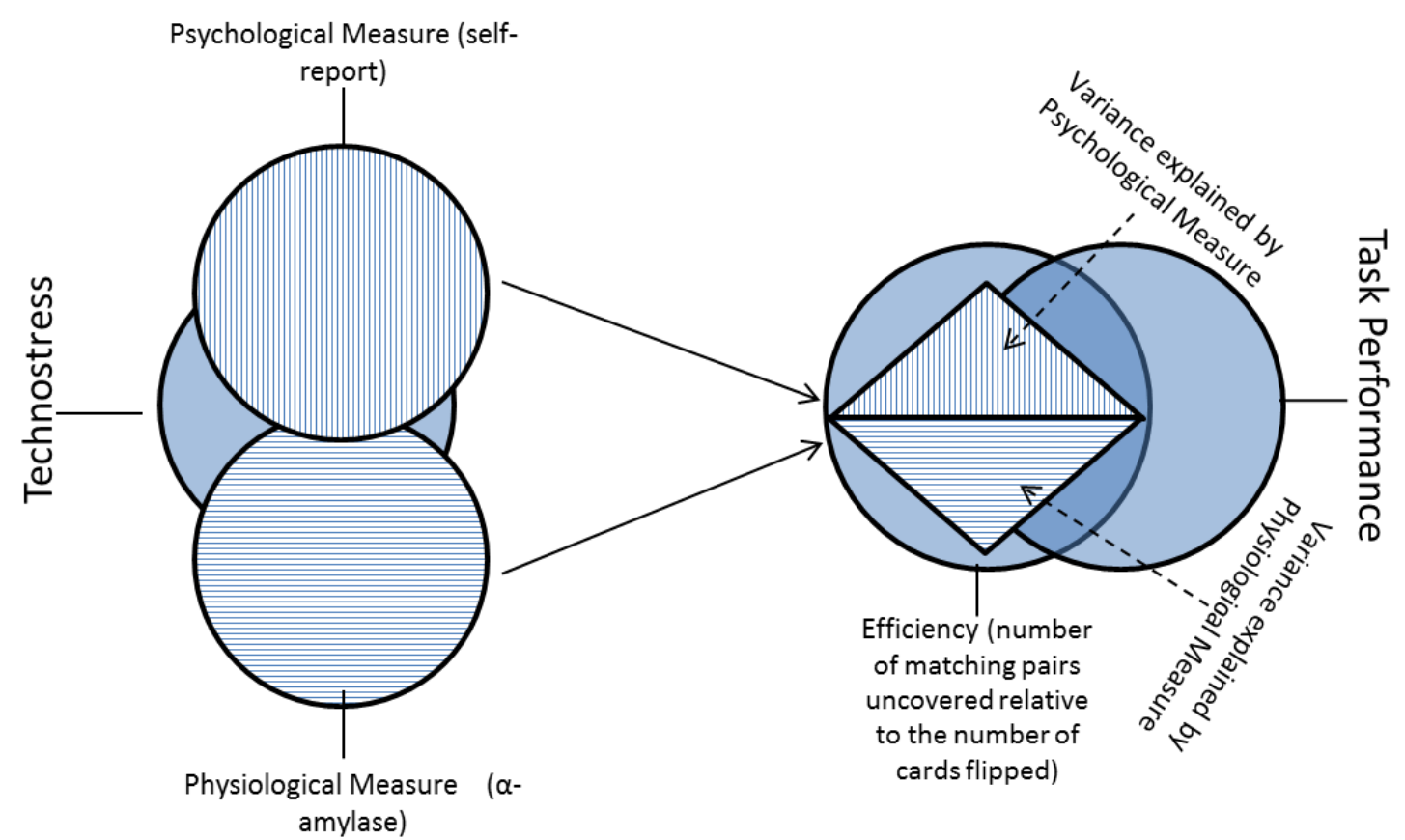

Figure 4. Illustration of Our Stress Variables as Complements in the Prediction of Task Performance

Based on correlational and hierarchical regression analyses, our findings indicate-consistent with Dimoka et al. (2012) - that differences between physiological and psychological measures do not necessarily imply that either measure is better or more valid than the other; rather, our findings suggest that there is a need for the holistic representation of IS constructs through both kinds of measures, especially when assessing complex IS constructs that are difficult to capture completely (or holistically) with a single data source. Thus, IS research would benefit from using both measures, if possible, in the same study to improve the predictive power of the research instruments employed. Additionally, this approach would improve the content validity of the research instrument. Content validity generally refers to the extent to which a research instrument represents all facets of a given construct. On the basis of our findings, a measure of technostress may lack content validity if it only captured the conscious 
dimension of technostress and failed to consider the unconscious dimension. Since psychological and physiological measures of IS constructs together can evaluate both the conscious and unconscious dimensions, their combined use may improve the content validity of IS research.

\subsection{Implications for Research and Practice}

Extending the methodological expertise of the IS field to physiological measures raises three main issues: measurement issues, longitudinal design issues, and issues of effectively combining psychological and physiological measures (Cooper et al., 2001; Fried et al., 1984). Concerning measurement issues, physiological data are not perfectly reliable; three key factors affect their reliability. First, stable factors such as individual differences in susceptibility to physiological symptoms (e.g., genetic tendency) need to be accounted for. Second, transitory factors such as context (e.g., physical exertion, temperature, substance consumption) need to be considered. Lastly, procedural factors such as taking pre-task measures and allowing for an appropriate amount of time to elapse between different measurements are important (Fried et al., 1984). Further, longitudinal studies are needed even for physiological measures to clarify directions of causality and disentangle their complex interactions (e.g., between the brain systems and the hormonal systems) (Fried et al., 1984; Schultheiss \& Stanton, 2009). For example, there is a reciprocal relationship between hormonal changes and brain activity (Riedl, 2013), which suggests that longitudinal research is needed to determine the direction of causality for a certain phenomenon that involves both levels of analysis. Finally, to effectively combine physiological and psychological measures, IS research may benefit from taking a test battery approach including several different psychological and physiological measures; this approach has the potential to shed further light on the link between these two different types of measures, on the value of contrasting them, and on their predictive abilities (Cooper et al., 2001).

If using both types of data in the same study is not possible due to resource constraints (e.g., time or funding constraints), the type to use could be selected on the basis of the research objective and the referent fields that inform the study. This idea is consistent with monists (e.g., Davidson, 2008), who argue that aspects of the world can be considered either physiologically or psychologically depending on whether one is interested in their relation to physical things in the world or in their link to the perceiver. For example, technostress research has primarily been informed by Psychology, which renders psychological measures of stress effective since these can be expected to relate to other concepts in a psychological nomological net (e.g., Ayyagari et al., 2011; Ragu-Nathan et al., 2008; Tarafdar et al., 2010). However, one study on technostress (Riedl et al., 2012) was informed by endocrinological theory (Dickerson \& Kemeny, 2004) and, as a result, successfully employed a biological measure of stress in a biological nomological net. In doing so, this one study complemented psychological technostress research by adding relevant explanatory factors in the form of bodily functions and processes. Overall, IS research is left to search for logical patterns in mixed-methods results, whether it seeks convergent validation or holistic representation (Jick, 1979). Thus, one can begin to view IS researchers as builders and creators that piece together many pieces of a complex puzzle into a coherent whole. It is in this respect that the first-hand knowledge drawn from NeurolS methods can become critical: they help to uncover a greater part of the puzzle that IS phenomena and their consequences represent.

A more holistic understanding of IS phenomena resulting from the use of traditional and NeurolS methods along with their corresponding theories may also enhance the effectiveness of managerial interventions designed to impact technology usage behaviors in organizations. For example, our findings suggest that managers attempting to assess the occurrence of technostress in their employees may obtain an incomplete picture if they rely on self-reports of their workforce alone. Such self-reports could indicate that no technostress is present when, in reality, employees experience significant stress levels without being consciously aware of them. As a result of this unawareness of physiological stress symptoms, significant health problems could result for the employees, with negative organizational consequences (Riedl, 2013).

\subsection{Future Research}

While we were able to shed some initial light on the role of NeurolS and its contribution to IS research with this study, future research is warranted to extend our findings. Perhaps most importantly, a study 
is warranted that seeks to determine whether our findings extend to other research contexts and neurophysiological tools. Despite this more obvious extension, other research ideas warrant examination; for example, it may be that in certain situations the swapping of psychological and physiological measures is perfectly reasonable, although there is no certainty that the measures are ever interchangeable (Rich et al., 1999). While our results suggest that psychological and physiological measures of technostress are "apples and oranges", it is unknown whether "apples and apples" may sometimes occur. More specifically, the relationship/correlation between both types of measures may depend on certain moderators (Heneman, 1986; Rich et al., 1999), including certain individual difference variables, rating method, and rating format. Figure 5 shows these proposed moderating factors.

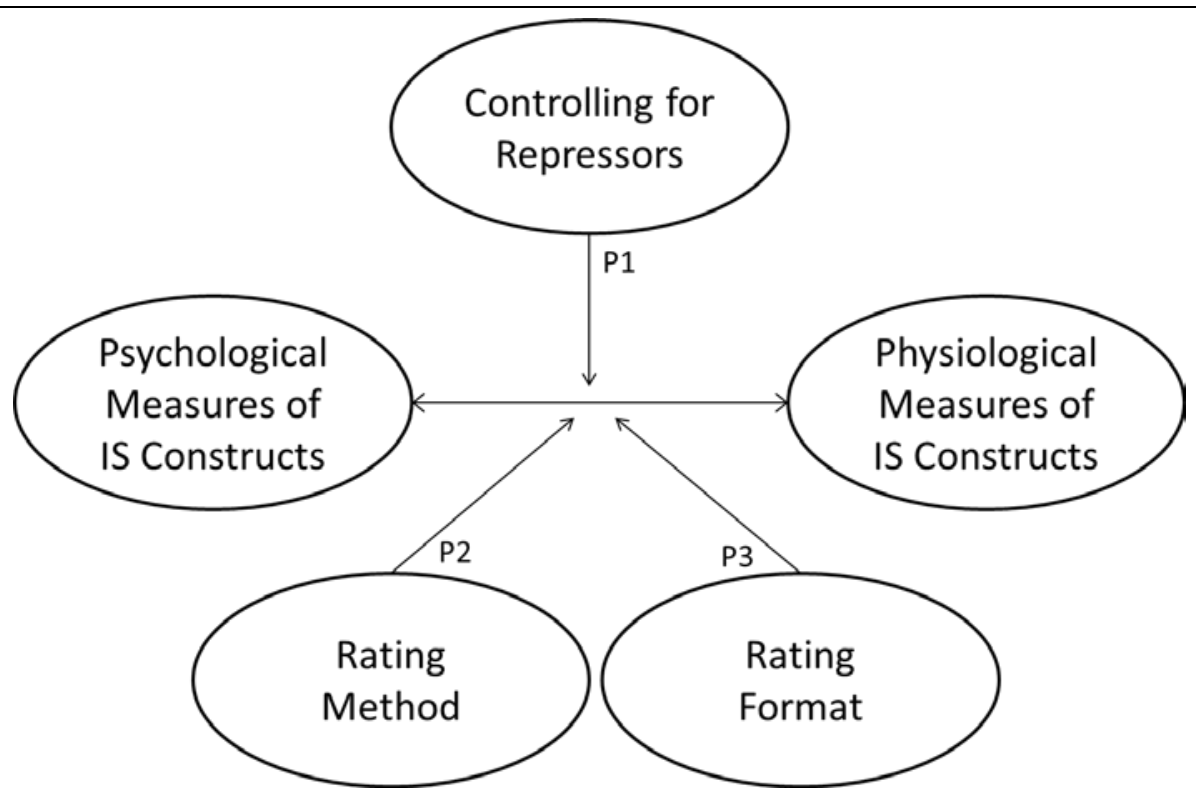

Figure 5. Proposed Moderators of the Relationship Between Self-Reported and NeurolS Measures

Concerning individual difference variables in the context of technostress, there is a line of research suggesting that some individuals show a stronger tendency to be unaware of emotional causes of arousal than others (Derakshan, Eysenck, \& Myers, 2007). Specifically, individuals called "repressors", who use a repressive style to cope with stress, tend to perceive and report low anxiety despite high levels of physiological indicators of anxiety. These individuals show strong physiological responses to stressors, but they use attentional and interpretive biases to neglect these threatening stimuli. As a result of their avoidance-oriented cognitive biases (attentional, interpretive, and memory), the conscious experience of anxiety is inhibited (Derakshan et al., 2007). In consequence, repressors show a particularly large discrepancy between psychological and physiological measures of stress and anxiety, which suggests that the correlation between both types of measures should be particularly small for these individuals. Accordingly, controlling for this individual difference (i.e., the use of a repressing coping style) or closely related ones should generally increase the correlation between both types of measures. Formally:

Proposition 1: Controlling for individuals who use a repressive coping style moderates the correlation between psychological and physiological measures of IS constructs such that the correlation is stronger when this individual difference is controlled for than when it is not.

Further, it is possible that a study's rating method significantly impacts the magnitude of the correlation between psychological and physiological measures of IS constructs. This idea is consistent with the "cognitive complexity" hypothesis introduced by Feldman (1981) that argues that 
simpler psychological measures or scales are generally more accurate. In accordance with this hypothesis, ratings that are easy for the rater to process (e.g., likert-type scales) should constitute more accurate reflections of physiological indications than ratings that place a heavy cognitive burden on the subject (e.g., drag and drop rankings). This general hypothesis is consistent with the findings of Ortiz de Guinea et al. (2013) in the context of IS research. Hence, the correlation between both types of measures should be larger when ratings place a lighter cognitive burden on the subject than when they place a heavier cognitive burden on the subject. Formally:

Proposition 2: Rating method moderates the correlation between psychological and physiological measures of IS constructs such that the correlation is stronger when the psychological measure is assessed using a simple method rather than when a complex method is used.

Moreover, it is possible that a study's rating format significantly impacts the magnitude of the correlation between psychological and physiological measures of IS constructs. This idea is, again, consistent with the "cognitive complexity" hypothesis introduced by Feldman (1981). More specifically, it has been argued that, due to the substantial demands for observation, storage, retrieval, and judgment involved in self-reported ratings, any rating format that simplifies the rating task should strengthen the correlation between psychological and physiological measures (Heneman, 1986). This idea is also consistent with the findings of Ortiz de Guinea et al. (2013). Two major formats appear to dominate ratings of organizational and IS constructs, including overall and composite rating formats (Rich et al., 1999). Overall ratings require the subjects to rate an overall, higher-order concept; that is, to develop broad conclusions regarding the overall level of, for example, technostress. By contrast, composite ratings, which are often used in IS research, are based on a variety of specific items representing lower-order measures (Rich et al., 1999). Consistent with the cognitive complexity argument, there is reason to believe that composite ratings are generally more accurate reflections of physiological indications than overall ratings. Hence, the correlation between both types of measures should be larger for composite than for overall ratings. Thus:

Proposition 3: Rating format moderates the correlation between psychological and physiological measures of IS constructs such that the correlation is stronger when the psychological measure is assessed using a composite rather than an overall rating format.

Overall, future research could examine to what extent the results reported here for the relationship (or correlation) between psychological and physiological measures of technostress depend on certain individual differences (e.g., repressive coping styles), rating methods, and rating formats. Such an examination could bound the applicability of our findings (Bacharach, 1989), and it could yield a more detailed and specific understanding of the conditions under which psychological and physiological measures of IS constructs do or do not correlate.

Additionally, future research could adopt a broader conceptualization of complementarity than was done here. Consistent with the NeurolS literature (e.g., Riedl et al., 2010a), we use the term "complement" in accordance with its basic dictionary meaning to imply that a physiological measure complements a psychological measure when it completes the psychological measure by explaining additional variance in IS dependent variables (i.e., complementarity has been interpreted as incremental variance explained by a physiological measure over and above a psychological measure). However, in accordance with complementarity theory (e.g., Milgrom \& Roberts, 1995), the term "complement" can also be used for a variable that interacts with another one synergistically (i.e., the whole is more than the sum of its parts). Future research could examine the possibility of interaction effects between psychological and physiological measures of IS constructs, where a physiological measure may strengthen the effect of a psychological measure on an outcome variable (for example, physiological stress may strengthen the impact of psychological stress on performance).

As an initial response to the question of interaction effects, one could argue that psychological and physiological measures of IS constructs should not interact in their prediction of an outcome variable because the conscious (human psychology) and the unconscious (human physiology) systems have 
often been assumed and found to operate autonomously and independently of each other. For example, Brenner, Beauchaine, and Sylvers (2005) found that psychological and physiological measures of behavioral approach and inhibition reactivity are independent. Consistent with this notion, our data did not support the idea that psychological and physiological measures of IS constructs interact in the prediction of a dependent variable. We conducted a post-hoc analysis, adding a fourth step to our hierarchical regression model that included the product term between psychological and physiological stress. The results of this post-hoc analysis revealed that the interaction term did not explain significant incremental variance in performance. After Step 4, with the interaction term added to the prediction of performance, $R^{2}=.35$ (adjusted $R^{2}=.19$ ), Finc $(1,48)=0.052, p>.05$. Thus, the addition of the interaction term to the regression equation did not result in a significant increment in $\mathrm{R}^{2}$. However, it also appears reasonable to assume that subjects who show strong hormonal reactivity to computer hassles and who indicate not to be stressed at all might turn out to be differentially vulnerable to job-related psychiatric illnesses than subjects who show strong hormonal reactivity to computer hassles and who indicate to be highly stressed ${ }^{15}$. Hence, more work is needed in this area, and future research could shed more light on the possibility of interaction effects between psychological and physiological measures of IS constructs.

\subsection{Limitations and Strengths}

As with any research, our study has its limitations. Five primary limitations should be considered. First, our study relied on student data and, thus, it is not clear to what extent the results can generalize to the workplace. Yet, much like corporate employees, students are human beings and users of technology who experience technostress (Weil \& Rosen, 1997). Second, we conducted this study in the context of technostress so that it is currently unclear to what extent the results can generalize to other IS phenomena, such as technology acceptance. Future research could investigate this generalization.

Third, the absence of a treatment effect was a limitation of this study. A possible reason for this finding is that student subjects can, generally, easily disregard and even completely ignore interrupting stimuli on a computer display due to their young age; young adults have strong selective attention abilities in terms of inhibitory control, which allows them to concentrate on a task at hand even in the presence of interruptions (Darowski, Helder, Zacks, Hasher, \& Hambrick, 2008). This ability only declines with advanced age (Darowski et al., 2008). A likely further reason is that student subjects, generally, have a lot of computer experience and computer self-efficacy combined with low computer anxiety (Czaja et al., 2006), further limiting their stress reactions to interruptions. Nevertheless, the joint presence of performance-based incentives and time pressure during the execution of a rapid succession of complex computer-based actions provided study participants with a sufficiently challenging technological task, prompting variations in stress responses (both psychological and physiological), which we subsequently examined as independent predictors of performance on this task. Additionally, interruptions may impact stress only indirectly, mediated by relevant cognitive mechanisms, not directly (Monat et al., 2007). Thus, a more detailed, differentiated design using relevant mediators and moderators may have been more likely to yield the expected results. For example, since older adults show much lower inhibitory control and much lower computer experience and computer self-efficacy than younger adults but significantly higher computer anxiety (Czaja et al., 2006; Darowski et al., 2008), they may be substantially more stressed by interruptions. Future research may examine these age-related differences; in fact, Tarafdar et al. (2007) has called for an examination of the role of age in technostress. Another aspect to examine by future work is the notion that interruptions may impact stress only indirectly through increases in mental workload or personenvironment misfit, rather than directly (French, Caplan, \& Van Harrison, 1982).

Fourth, since the psychological measure asked the subjects to report on their perception of a specific situation (i.e., the experimental task), the subjects could not be asked to rate this measure prior to that situation (i.e., pre-task), which implies a potential loss of information in the psychological measure. As a result of this potential loss of information, this study's lack of a pre-task measurement of psychological stress is a limitation. However, we made an effort to mitigate this limitation by considering certain aspects in our study design. First, subjects can readily perceive certain situations, such as experimental tasks, in certain ways, and they can adequately report on their perceptions of

${ }^{15}$ We thank an anonymous member of the review panel for pointing out this important aspect. 
these situations or tasks when the self-report occurs immediately following the task (Schwarz, 2007), as was the case in our study. Second, the endpoint, at which psychological stress was measured, was the time point of primary interest to this study. Third, in psychometrics, administering the same measure pre and post-task can lead to substantial problems that our design avoided, problems such as testing effects where the repeated administration of the same measure can bias the results (e.g., because learning takes place and because pre-task administration can prime the subjects to look more strongly for specific task elements such as stress perceptions when performing the task, potentially biasing post-task perceptions) (Shadish, Cook, \& Campbell, 2003). Thus, post-only designs such as the one employed here are often considered robust, especially in light of the treatment effects that can be introduced with a pre-treatment assessment (Shadish et al., 2003). Lastly, the psychological measure we employed is consistent with much stress-related experimental research (e.g., Kirschbaum et al., 1995; Plante \& Ford, 2000) in that it asked the subjects how much stress they experienced in response to the task they had just performed. Still, future work should employ a pre-task measurement of psychological stress.

Finally, our study was limited to SAA as a physiological measure, which means that it is currently unclear to what extent the results can generalize to other physiological tools such as electrocardiogram (ECG), skin conductance response (SCR), or brain imaging tools (e.g., fMRI). For example, using ECG, researchers can directly measure whether a certain interface increases a subject's heart rate, which could be an indicator of technostress (Riedl, 2013). Similarly, SCR allows researchers to capture technostress levels (Riedl et al., 2013). However, note that different physiological levels of analysis, such as the central nervous system, the autonomic nervous system, the endocrine system, the body immune system, and the genetic system, are closely interrelated (e.g., Cacioppo et al., 2000; Riedl, 2013; Schultheiss \& Stanton, 2009). For example, genes influence hormones, which, in turn, impact brain activity since certain regions in the brain have receptors for certain hormones (Riedl, 2013). At the same time, hormones are impacted by brain activity since the brain regulates the production and release of hormones (Cacioppo et al., 2000; Riedl, 2013), which suggests the existence of a reciprocal relationship between, for example, hormones and brain activity. Thus, while all these aspects of human physiology are distinct, they are also closely interrelated. Consequently, the study conducted here may offer valuable first insights into the role of NeurolS in IS research despite its focus on salivary assessments and sAA.

Notwithstanding these limitations, our study also has several important strengths. Perhaps most importantly, we effectively reduced common threats to internal validity by employing a rigorous research design that was consistent with its theoretical frame (i.e., the triangulation approach). We circumvented common method bias by employing fundamentally different methods for collecting the stress-related and performance-related data. More specifically, we collected the psychological stressrelated data using psychometrics, the physiological stress-related data using cutting-edge biological metrics, and a computer algorithm objectively collected performance-related data by counting the number of matching pairs uncovered relative to the number of cards flipped. As a result, we effectively circumvented common method bias.

In addition to this strength, for this study, we used a homogenous sample consisting of university students, and effectively controlled for demographic variables that could have otherwise influenced our results. Using student subjects was further consistent with the focus of this study, which was to clarify the source of NeurolS' contribution to an improved explanation and prediction of IS phenomena rather than on workplace design. As Compeau, Marcolin, Kelley, and Higgins (2012) indicate in their commentary on the use of student subjects in IS research, using students is appropriate when external validity is not the goal of the research, as in this study. This notion is also consistent with Mook's (1983) seminal work on external validity.

Moreover, the technostress phenomenon, for which complementarity was demonstrated, constituted an important and relevant context for this study given 1) the phenomenon's significance for our research objective (i.e., both psychological and physiological measures of stress are highly relevant to the technostress phenomenon) (Cacioppo et al., 2000; Cooper et al., 2001; Riedl, 2013) and 2) the phenomenon's practical significance for organizations (e.g., Ayyagari et al., 2011; Tarafdar et al., 2010). Further, the technostress phenomenon is similar in nature to several other phenomena studied 
by IS researchers, such as technology acceptance and trust (e.g., Riedl \& Javor, 2012; Riedl, Hubert, \& Kenning, 2010b; Riedl, Mohr, Kenning, Davis, \& Heekeren, 2011, 2014), all of which relate to peoples' interactions with technology. As a result of this similarity, our findings may extend to other important IS phenomena.

Furthermore, our physiological measure of stress (i.e., sAA) was particularly useful for our study context (i.e., technostress) since salivary assessments do not, by themselves, induce stress and bias the results of research on technostress (Riedl, 2013). More specifically, since alpha-amylase can be captured using saliva, it is a non-invasive, uncomplicated, and relatively quick measure of technostress (Riedl, 2013). As a result, the data collection method by itself is not very likely to create an alternative explanation for stress effects when using SAA. By contrast, most other neurophysiological tools, including ECG and SCR, use various sensors attached to the human body that may by themselves induce stress and, as a result, may bias the results (Dimoka et al., 2012). The same holds true for blood samples (Riedl, 2013); hence, salivary measures such as sAA were particularly useful for this study.

Finally, the use of a game-like computer-based task was a strength of our study that was, furthermore, consistent with recent experimental research in IS (e.g., Dabbish \& Kraut, 2008; Liu et al., 2013; McFarlane, 2002), Psychology (e.g., Baker-Ward \& Ornstein, 1988; Schumann-Hengsteler, 1996; Washburn et al., 2007), and Bio-Behavioral Studies (Granger et al., 2006; Granger et al., 2007). Game-like computer-based tasks are intrinsically motivating and provide continuity and context for responding (Washburn, 2003); as a result, subjects stay engaged over the long durations required by experiments. Further, subjects take the experimental task seriously and stay focused on it, which effectively reduces the likelihood that researchers obtain misleading results (Washburn, 2003).

\section{Conclusion}

We identified differing viewpoints in NeurolS research with respect to the relationship between the emerging physiological measures and the traditional psychological measures of IS constructs. These differing viewpoints indicate a lack of clarity regarding the value that NeurolS research has for the IS community and the contribution it can make to IS research (Dimoka et al., 2012). Motivated by this lack of clarity, we examined whether both kinds of measures constitute alternatives or complements in the prediction of theoretically-related outcomes. We demonstrated for the case of technostress that physiological and psychological measures can diverge. This divergence precludes them from constituting alternative forms of measurement, and it suggests that they could be complementary. We then demonstrated complementarity by using the physiological measure to explain additional variance in performance on a computer-based task, variance to which the psychological measure was blind. In effect, our physiological measure captured aspects of stress of which the subjects were generally not aware. Hence, the value of NeurolS research lies in its capacity to complement traditional IS methods so that a more complete understanding of IS phenomena can be obtained and more powerful predictive relationships achieved.

Overall, our findings indicate that physiological and psychological measures of such IS constructs as technostress may not be interchangeable and that, in fact, both types of measures together can explain higher levels of variance in IS dependent variables than either one can alone. In doing so, our findings shift the debate on the role of NeurolS in IS research from one of mere measurement accuracy to one of theoretical richness and more complete prediction and explanation of the consequences of such IS phenomena as technostress.

Based on the results of this study, we conclude that IS research on technostress has missed a vital part of the phenomenon by focusing on the conscious (i.e., psychological or self-reported) "tip of the iceberg". Hence, it is more than timely to start exploring the underwater part of that "iceberg" by testing the physiological effects of unconscious technostress. Over time, using both measures and combining the insights provided by them may yield a more holistic understanding of peoples' psychological perceptions of technology and their physiological reactions to it, a necessity in fully understanding the impact of technology on individuals. 
Tams et al. / NeuroIS-Altemative or Complement?

\section{Acknowledgements}

We are indebted to the editors and reviewers for the help they provided throughout the review process; the review panel did an excellent job. 


\section{References}

Appan, R., \& Browne, G. J. (2012). The impact of analyst-induced misinformation on the requirements elicitation process. MIS Quarterly, 36(1), 85-106.

Ayyagari, R., Grover, V., \& Purvis, R. (2011). Technostress: Technological antecedents and implications. MIS Quarterly, 35(4), 831-858.

Bacharach, S. B. (1989). Organizational theories: Some criteria for evaluation. Academy of Management Review, 14(4), 496-515.

Baker-Ward, L., \& Ornstein, P. A. (1988). Age differences in visual-spatial memory performance: Do children really out-perform adults when playing concentration? Bulletin of the Psychonomic Society, 26(4), 331-332.

Bargh, J. A., \& Morsella, E. (2008). The unconscious mind. Perspectives on Psychological Science: A Journal of the Association for Psychological Science, 3(1), 73-79.

Beauducel, A., Debener, S., Brocke, B. \& Kayser, J. (2000). On the reliability of augmenting / reducing: Peak amplitudes and principal component analysis of auditory evoked potentials. Journal of Psychophysiology, 14, 226-240.

Beehr, T. A. (1995). Psychological stress in the workplace. Routledge London.

Bommer, W. H., Johnson, J. L., \& Rich, G. A. (1995). On the interchangeability of objective and subjective measures of employee performance: A meta-analysis. Personnel Psychology, 48, 587-605.

Brenner, S. L., Beauchaine, T. P., \& Sylvers, P. D. (2005). A comparison of psychophysiological and self-report measures of BAS and BIS activation. Psychophysiology, 42(1), 108-115.

Brosschot, J. F. (2010). Markers of chronic stress: Prolonged physiological activation and (un)conscious perseverative cognition. Neuroscience \& Biobehavioral Reviews, 35(1), 46-50.

Brosschot, J. F., Verkuil, B., \& Thayer, J. F. (2010). Conscious and unconscious perseverative cognition: Is a large part of prolonged physiological activity due to unconscious stress? Journal of Psychosomatic Research, 69(4), 407-416.

Cacioppo, J. T., Berntson, G. G., Sheridan, J. F., \& McClintock, M. K. (2000). Multilevel integrative analyses of human behavior: Social neuroscience and the complementing nature of social and biological approaches. Psychological Bulletin, 126(6), 829-843.

Cacioppo, J. T., Tassinary, L. G., \& Berntson, G. G. (2007). Psychophysiological science: Interdisciplinary approaches to classic questions about the mind. In J. T. Cacioppo, L. G. Tassinary \& G. G. Berntson (Eds.), (pp. 1-16). New York, NY US: Cambridge University Press.

Campbell, D. T., \& Fiske, D. W. (1959). Convergent and discriminant validation by the multitraitmultimethod matrix. Psychological Bulletin, 56(2), 81-105.

Ceccagnoli, M., Forman, C., Huang, P., \& Wu, D. J. (2012). Cocreation of value in a platform ecosystem: The case of enterprise software. MIS Quarterly, 36(1), 263-290.

Chang, C., Rosen, C. C., \& Levy, P. E. (2009). The relationship between perceptions of organizational politics and employee attitudes, strain, and behavior: A meta-analytic examination. Academy of Management Journal, 52(4), 779-801.

Chilton, M. A., Hardgrave, B. C., \& Armstrong, D. J. (2005). Person-job cognitive style fit for software developers: The effect on strain and performance. Journal of Management Information Systems, 22(2), 193-226.

Churchill Jr., G. A. (1979). A paradigm for developing better measures of marketing constructs. Journal of Marketing Research, 16(1), 64-73.

Cohen, J., Cohen, P., West, S. G., \& Aiken, L. S. (2003). Applied multiple regression/correlation analysis for the behavioral sciences (3rd ed.). Mahwah, NJ US: Lawrence Erlbaum Associates Publishers.

Compeau, D., Marcolin, B., Kelley, H., \& Higgins, C. (2012). Generalizability of information systems research using student Subjects-a reflection on our practices and recommendations for future research. Information Systems Research, 23(4), 1093-1109.

Cook, T. D., \& Campbell, D. T. (1979). Quasi-experimentation: Design \& analysis issues for field settings. Chicago, IL: Rand McNally.

Cooper, C. L., Dewe, P. J., \& O'Driscoll, M. P. (2001). Organizational stress: A review and critique of theory, research, and applications. Thousand Oaks, CA: Sage.

Cronbach, L. J., \& Meehl, P. E. (1955). Construct validity in psychological tests. Psychological Bulletin, 52(4), 281.

Czaja, S. J., Charness, N., Fisk, A. D., Hertzog, C., Nair, S. N., Rogers, W. A., \& Sharit, J. (2006). Factors predicting the use of technology: Findings from the center for research and education on aging and technology enhancement (create). Psychology and Aging, 21(2), 333-352. 
Dabbish, L., \& Kraut, R. (2008). Awareness displays and social motivation for coordinating communication. Information Systems Research, 19(2), 221-238.

Darowski, E. S., Helder, E., Zacks, R. T., Hasher, L. \& Hambrick, D. Z. (2008). Age-related differences in cognition: The role of distraction control, Neuropsychology, 22(5), 638-644.

Davidson, D. (2008). Mental events. In W. G. Lycan, \& J. J. Prinz (Eds.), Mind and cognition (3rd ed., pp. 55-65). Malden: Blackwell Publishing.

Dennis, A. R., \& Kinney, S. T. (1998). Testing media richness theory in the new media: The effects of cues, feedback, and task equivocality. Information Systems Research, 9(3), 256-274.

Denzin, N. K. (1989). The research act: A theoretical introduction to sociological methods 3rd ed; . United States of America: Prentice-Hall.

Derakshan, N., Eysenck, M. W., \& Myers, L. B. (2007). Emotional information processing in repressors: The vigilance-avoidance theory. Cognition and Emotion, 21(8), 1585-1614.

Dickerson, S. S., \& Kemeny, M. E. (2004). Acute stressors and cortisol responses: A theoretical integration and synthesis of laboratory research. Psychological Bulletin, 130(3), 355-391.

Dijksterhuis, A., \& Nordgren, L. F. (2006). A theory of unconscious thought. Perspectives on Psychological Science (Wiley-Blackwell), 1(2), 95-109.

Dimoka, A., Pavlou, P. A., \& Davis, F. D. (2011). NeurolS: The potential of cognitive neuroscience for information systems research. Information Systems Research, 22(4), 687-702.

Dimoka, A. (2012). How to conduct a functional magnetic resonance (fmri) study in social science research. MIS Quarterly, 36(3), 811-A11.

Dimoka, A., Banker, R. D., Benbasat, I., Davis, F. D., Dennis, A. R., Gefen, D., Weber, B. (2012). On the use of neurophysiological tools in is research: Developing a research agenda for neurois. MIS Quarterly, 36(3), 679-A19.

Eden, D. (1982). Critical job events, acute stress, and strain: A multiple interrupted time series. Organizational Behavior \& Human Performance, 30, 312-329.

Farrar, J. T. P., LaMoreaux, L., Werth, J. L. \& Poole, R. M. (2001). Clinical importance of changes in chronic pain intensity measured on an 11-point numerical pain rating scale. Pain, 94(2), 149-158.

Faul, F., Erdfelder, E., Buchner, A., \& Lang, A.-G. (2009). Statistical power analyses using G*Power 3.1: Tests for correlation and regression analyses. Behavior Research Methods, 41(4), 1149-1160.

Feldman, J. M. (1981). Beyond attribution theory: Cognitive processes in performance appraisal. Journal of Applied Psychology, 66(2), 127-148.

Fleising, U., \& Labovitz, S. (1976). A misapplication of biological concepts and data. American Sociological Review, 41(3), 548-551.

Folkman, S., \& Lazarus, A. L. (1984). Stress, appraisal and coping. New York: Springer.

French, J. R. P., Caplan, R. D., \& Van Harrison, R. (1982). The mechanisms of job stress and strain. Chichester, England: J. Wiley.

Fried, Y., Rowland, K. M., \& Ferris, G. R. (1984). The physiological measurement of work stress: A critique. Personnel Psychology, 37, 583-615.

Granger, D. A., Kivlighan, K. T., Blair, C., El-Sheikh, M., Mize, J., Lisonbee, J. A., Buckhalt, J. A., Stroud, L. R., Handwerger, K., \& Schwartz, E. B. (2006). Integrating the measurement of salivary a-amylase into studies of child health, development, and social relationships. Journal of Social and Personal Relationships, 23(2), 267-290.

Granger, D. A., Kivlighan, K. T., el-Sheikh, M., Gordis, E. B., \& Stroud, L. R. (2007). Salivary alphaamylase in biobehavioral research: Recent developments and applications. Annals of the New York Academy of Sciences, 1098, 122-144.

Heneman, R. L. (1986). The relationship between supervisory ratings and results-oriented measures of performance: A meta-analysis. Personnel Psychology, 39, 811-826.

Jick, T. D. (1979). Mixing qualitative and quantitative methods: Triangulation in action. Administrative Science Quarterly, 24(4), 602-611.

Katona, G. (1976). On subjective and objective measures. American Psychologist, 31(8), 617-617.

Kim, J. (2000). Mind in a physical world: An essay on the mind-body problem and mental causation. Cambridge: MIT Press.

Kirschbaum, C., Klauer, T., Filipp, S. H., \& Hellhammer, D. H. (1995). Sex-specific effects of social support on cortisol and subjective responses to acute psychological stress. Psychosomatic Medicine, 57(1), 23-31. 
Korunka, C., Huemer, K. H., Litschauer, B., Karetta, B., \& Kafka-Lützow, A. (1996). Working with new technologies: Hormone excretion as an indicator for sustained arousal. A pilot study. Biological Psychology, 42(3), 439-452.

Lang, J., Thomas, J. L., Bliese, P. D., \& Adler, A. B. (2007). Job demands and job performance: The mediating effect of psychological and physical strain and the moderating effect of role clarity. Journal of Occupational Health Psychology, 12(2), 116-124.

Lang, P. J., Greenwald, M. K., Bradley, M. M., \& Hamm, A. O. (1993). Looking at pictures: Affective, facial, visceral, and behavioral reactions. Psychophysiology, 30(3), 261-273.

Lev-ari, S., Maimon, Y., \& Yaal-Hahoshen, N. (2006). Long-term survival of a patient with widespread metastases from epithelial ovarian carcinoma receiving mind-body therapies: Case report and review of the literature. Integrative Cancer Therapies, 5(4), 395-399.

Liu, D., Li, X., \& Santhanam, R. (2013). Digital games and beyond: What happens when players compete. MIS Quarterly, 37(1), 111-124.

Loos, P., Riedl, R., Müller-Putz, G. R., vom Brocke, J., Davis, F. D., Banker, R. D., \& Léger, P.-M. (2010). NeurolS: Neuroscientific approaches in the investigation and development of information systems. Business \& Information Systems Engineering, 2(6), 395-401.

Lord, R. G., \& Kanfer, R. (2002). Emotions and organizational behavior. Emotions in the Workplace: Understanding the Structure and Role of Emotions in Organizational Behavior, 5-19.

Loucks, R. B. (1941). The contribution of physiological psychology. Psychological Review, 48(2), 105-126.

McEwen, B. S. (2006). Protective and damaging effects of stress mediators: Central role of the brain. Dialogues in Clinical Neuroscience, 8(4), 367.

McFarlane, D. C. (2002). Comparison of four primary methods for coordinating the interruption of people in human-computer interaction. Human-Computer Interaction, 17(1), 63-139.

Milgrom, P., \& Roberts, J. (1995). Complementarities and fit: Strategy, structure, and organizational change in manufacturing. Journal of Accounting and Economics, 19(2-3), 179-208.

Monat, A., Lazarus, R. S., \& Reevy, G. (2007). In Monat A., Lazarus R. S. and Reevy G. (Eds.), The praeger handbook on stress and coping (Vol. 2). Westport, CT: Praeger Publishers.

Mook, D. G. (1983). In defense of external invalidity. American Psychologist, 38(4), 379-387.

Moore, J. E. (2000). One road to turnover: An examination of work exhaustion in technology professionals. MIS Quarterly, 24(1), 141-168.

Nater, U., \& Rohleder, N. (2009). Salivary alpha-amylase as a non-invasive biomarker for the sympathetic nervous system: Current state of research. Psychoneuroendocrinology, 34(4), 486-496.

Neupert, S. D., Miller, L. M. S., \& Lachman, M. E. (2006). Physiological reactivity to cognitive stressors: Variations by age and socioeconomic status. The International Journal of Aging and Human Development, 62(3), 221-235.

Nunnally, J. C. (1967). Psychometric theory. New York, NY US: McGraw-Hill.

Ortiz de Guinea, A., \& Webster, J. (2013). An investigation of information systems use patterns: Technological events as triggers, the effects of time, and consequences for performance. MIS Quarterly, 37(4), 1165-1188.

Ortiz de Guinea, A., Titah, R., \& Léger, P. (2013). Measure for measure: A two study multi-trait multi-method investigation of construct validity in IS research. Computers in Human Behavior, 29(3), 833-844.

Patterson, S. M., Krantz, D. S., Montgomery, L. C., Deuster, P. A., Hedges, S. M., \& Nebel, L. E. (1993). Automated physical activity monitoring: Validation and comparison with physiological and self-report measures. Psychophysiology, 30(3), 296-305.

Plante, T. G., \& Ford, M. (2000). The association between cardiovascular stress responsivity and perceived stress among subjects with irritable bowel syndrome and temporomandibular joint disorder: A preliminary analysis. International Journal of Stress Management, 7(2), 103-119.

Podsakoff, P. M., MacKenzie, S. B., Lee, J., \& Podsakoff, N. P. (2003). Common method biases in behavioral research: A critical review of the literature and recommended remedies. Journal of Applied Psychology, 88(5), 879-903.

Polites, G. L., \& Karahanna, E. (2012). Shackled to the status quo: The inhibiting effects of incumbent system habit, switching costs, and inertia on new system acceptance. MIS Quarterly, 36(1), 21-A13.

Ragu-Nathan, T., Tarafdar, M., Ragu-Nathan, B., \& Tu, Q. (2008). The consequences of technostress for end users in organizations: Conceptual development and empirical validation. Information Systems Research, 19(4), 417-433. 
Rich, G. A., Bommer, W. H., MacKenzie, S. B., Podsakoff, P. M., \& Johnson, J. L. (1999). Apples and apples or apples and oranges? A meta-analysis of objective and subjective measures of salesperson performance. Journal of Personal Selling \& Sales Management, 19(4), 41-52.

Riedl, R. (2009). Zum Erkenntnispotenzial der kognitiven Neurowissenschaften für die Wirtschaftsinformatik: Überlegungen anhand exemplarischer Anwendungen. NeuroPsychoEconomics, 4(1), 32-44.

Riedl, R. (2013). On the biology of technostress: Literature review and research agenda. The DATA BASE for Advances in Information Systems, 44(1), 18-55.

Riedl, R., Banker, R. D., Benbasat, I., Davis, F. D., Dennis, A. R., Dimoka, A., Gefen, D., Gupta, A., Ischebeck, A., Kenning, P., Müller-Putz, G., Pavlou, P. A., Straub, D. W., vom Brocke, J., Weber, B. (2010a). On the foundations of NeurolS: Reflections on the Gmunden Retreat 2009. Communications of AIS, 27, 243-264.

Riedl, R., Hubert, M., \& Kenning, P. (2010b). Are there neural gender differences in online trust? An fMRI study on the perceived trustworthiness of eBay offers. MIS Quarterly, 34(2), 397-428.

Riedl, R., \& Javor, A. (2012). The biology of trust: Integrating evidence from genetics, endocrinology and functional brain imaging. Journal of Neuroscience, Psychology, and Economics, 5(2), 63-91.

Riedl, R., Kindermann, H., Auinger, A., \& Javor, A. (2012). Technostress from a neurobiological perspective-system breakdown increases the stress hormone cortisol in computer users. Business \& Information Systems Engineering, 4(2), 61-69.

Riedl, R., Kindermann, H., Auinger, A., \& Javor, A. (2013). Computer breakdown as a stress factor during task completion under time pressure: Identifying gender differences based on skin conductance. Advances in Human-Computer Interaction, Article ID 420169.

Riedl, R., Mohr, P., Kenning, P., Davis, F. D., \& Heekeren, H. (2011). Trusting humans and avatars: Behavioral and neural evidence. Proceedings of the 32nd International Conference on Information Systems (ICIS).

Riedl, R., Mohr, P., Kenning, P., Davis, F. D., \& Heekeren, H. (2014). Trusting humans and avatars: A brain imaging study based on evolution theory. Journal of Management Information Systems, 30(4), 83-113.

Robinson, H. (1983). Aristotelian dualism. Oxford Studies in Ancient Philosophy, I, 123-22.

Salimetrics (2011). Saliva collection and handling advice. Retrieved from www. salimetrics.com

Schaufeli, W., Leiter, M., \& Kalimo, R. (1995). The general burnout inventory: A self-report questionnaire to assess burnout at the workplace. Paper presented at Work, Stress and Health.

Schultheiss, O. C., \& Stanton, S. J. (2009). Assessment of salivary hormones. In E. Harmon-Jones, \& J. S. Beer (Eds.), (pp. 17-44). New York, NY US: Guilford Press.

Schumann-Hengsteler, R. (1996). Children's and adults' visuospatial memory: The game concentration. Journal of Genetic Psychology, 157, 77-92.

Schwarz, N. (2007). Retrospective and concurrent self-reports: The rationale for real-time data capture. In A. A. Stone, S. S. Shiffman, A. Atienza, \& L. Nebeling (Ed.), The science of real-time data capture: Self-reports in health research (pp. 11-26). New York: Oxford University Press.

Shadish, W. R., Cook, T. D., \& Campbell, D. T. (2002). Experimental and quasi-experimental designs for generalized causal inference. Boston, MA: Houghton, Mifflin and Company.

Spearman, C. (1904). "General intelligence," objectively determined and measured. The American Journal of Psychology, 15(2), 201-292.

Spector, P. E. (1999). Objective versus subjective approaches to the study of job stress. Journal of Organizational Behavior, 20(5), 737.

Straub, D., Boudreau, M. C., \& Gefen, D. (2004). Validation guidelines for is positivist research. Communications of AIS, 13, 380-427.

Strube, M. J., \& Newman, L. C. (2007). Psychometrics. In J. T. Cacioppo, L. G. Tassinary \& G. G. Berntson (Eds.), Handbook of psychophysiology (3rd ed., pp. 789-811). New York, NY: Cambridge University Press.

Suh, K., \& Lee, Y. E. (2005). The effects of virtual reality on consumer learning: An empirical investigation. Mis Quarterly, 29(4), 673-697.

Tabachnick, B. G., \& Fidell, L. S. (2007). Using multivariate statistics (5th ed.). Boston, MA: Allyn \& Bacon/Pearson Education.

Tam, K. Y., \& Ho, S. Y. (2006). Understanding the impact of web personalization on user information processing and decision outcomes. MIS Quarterly, 865-890. 
Tarafdar, M., Qiang, T. U., Ragu-Nathan, B., \& Ragu-Nathan, T. (2007). The impact of technostress on role stress and productivity. Journal of Management Information Systems, 24(1), 301-328.

Tarafdar, M., Tu, Q., \& Ragu-Nathan, T. (2010). Impact of technostress on end-user satisfaction and performance. Journal of Management Information Systems, 27(3), 303-334.

Theeuwes, J. (1991). Cross-dimensional perceptual selectivity. Perception \& Psychophysics, 50(2), 184-193.

Travers, C. J., \& Cooper, C. L. (1994). Psychophysiological responses to teacher stress: A move toward more objective methodologies. European Review of Applied Psychology / Revue Européenne De Psychologie Appliquée, 44(2), 137-146.

van Eck, M., Berkhof, H., Nicolson, N., \& Sulon, J. (1996). The effects of perceived stress, traits, mood states, and stressful daily events on salivary cortisol. Psychosomatic Medicine, 58(5), 447-458.

Van Harrison, R., Caplan, R. D., \& French, J. R. P. (1982). The mechanisms of job stress and strain Wiley.

Vedhara, K., Hyde, J., Gilchrist, I. D., Tytherleigh, M., \& Plummer, S. (2000). Acute stress, memory, attention and cortisol. Psychoneuroendocrinology, 25(6), 535-549.

Vedhara, K., Miles, J., Bennett, P., Plummer, S., Tallon, D., Brooks, E., Gale, L, Munnock, K., Schreiber-Kounine, C., Fowler, C., Lightman, S., Sammon, A., Rayter, Z., \& Farndon, J. (2003). An investigation into the relationship between salivary cortisol, stress, anxiety and depression. Biological Psychology, 62(2), 89-96.

vom Brocke, J., Riedl, R., \& Léger, P.-M. (2013). Application strategies for neuroscience in information systems design science research. Journal of Computer Information Systems, 53(3), 1-13.

Washburn, D. A., \& Gulledge, J. P. (1995). Game-like tasks for comparative research: Leveling the playing field. Behavior Research Methods, Instruments, \& Computers: A Journal of the Psychonomic Society, Inc, 27(2), 235-238.

Washburn, D. A. (2003). Presidential address: The games psychologists play (and the data they provide). Behavior Research Methods, Instruments \& Computers, 35(2), 185-193.

Washburn, D. A., Gulledge, J. P., James, F., \& Rumbaugh, D. M. (2007). A species difference in visuospatial working memory: Does language link "what" with "where"? International Journal of Comparative Psychology, 20(1), 55-64.

Weil, M. M., \& Rosen, L. D. (1997). Technostress: Coping with technology@ work@ home@ play J. Wiley New York, NY.

Wilder, J. (1958). Modern psychophysiology and the law of initial value. American Journal of Psychotherapy, 12, 199-221.

Wilson, E. O. (1977). Biology and the social sciences. Daedalus, 106(4), 127-140.

Zuckerman, M. (1992). What is a basic factor and which factors are basic? Turtles all the way down. Personality and Individual Differences, 13(6), 675-681. 


\section{Appendices}

\section{Appendix A: Databases Used for Literature Search}

Academic Search Alumni Edition, Academic Search Complete, Academic Search Premier, Agricola, Alt HealthWatch, America: History \& Life, Anthropology Plus, Applied Science \& Technology Full Text (H.W. Wilson), Art Full Text (H.W. Wilson), Art Index Retrospective (H.W. Wilson), Associates Programs Source, ATLA Religion Database with ATLASerials, Audiobook Collection (EBSCOhost), Avery Index to Architectural Periodicals, Biography Index Past and Present (H.W. Wilson), Biography Reference Bank (H.W. Wilson), Biological \& Agricultural Index Plus (H.W. Wilson), Book Review Digest Plus (H.W. Wilson), Business Abstracts with Full Text (H.W. Wilson), Business Source Alumni Edition, Business Source Complete, Business Source Premier, CINAHL Plus with Full Text, Cochrane Central Register of Controlled Trials, Cochrane Database of Systematic Reviews, Cochrane Methodology Register, Communication \& Mass Media Complete, Computer Science Index, Computer Source, Criminal Justice Abstracts with Full Text, Current Biography Illustrated (H.W. Wilson), Database of Abstracts of Reviews of Effects, eBook Collection (EBSCOhost), EconLit, Education Full Text (H.W. Wilson), Education Research Complete, Entrepreneurial Studies Source, ERIC, Essay and General Literature Index (H.W. Wilson), European Views of the Americas: 1493 to 1750, Family Studies Abstracts, Film \& Television Literature Index with Full Text, FSTA - Food Science and Technology Abstracts, Fuente Académica, Funk \& Wagnalls New World Encyclopedia, General Science Full Text (H.W. Wilson), GeoRef, GeoRef In Process, GreenFILE, Health Source - Consumer Edition, Health Source: Nursing/Academic Edition, Health Technology Assessments, Historical Abstracts, History Reference Center, Hospitality \& Tourism Complete, Human Resources Abstracts, Humanities \& Social Sciences Index Retrospective:, 1907-1984 (H.W. Wilson), Humanities Full Text (H.W. Wilson), Humanities International Index, Index to Legal Periodicals \& Books Full Text (H.W. Wilson), International Bibliography of Theatre \& Dance with Full Text, International Security \& Counter Terrorism Reference Center, Jewish Studies Source, L'Année philologique, LGBT Life with Full Text, Library Literature \& Information Science Full Text (H.W. Wilson), Library Literature \& Information Science Index (H.W. Wilson), Library, Information Science \& Technology Abstracts, Library, Information Science \& Technology Abstracts with Full Text, MAS Ultra - School Edition, MasterFILE Premier, MEDLINE, MEDLINE with Full Text, Mental Measurements Yearbook, Middle Search Plus, Military \& Government Collection, MLA Directory of Periodicals, MLA International Bibliography, Music Index, News (AP, UPI, etc.), Newspaper Source Plus, NHS Economic Evaluation Database, AHFS Consumer Medication Information, Play Index (H.W. Wilson), Political Science Complete, Primary Search, Professional Development Collection, PsycARTICLES, PsycCRITIQUES, Psychology and Behavioral Sciences Collection, PsycINFO, PsycTESTS, Readers' Guide Full Text Mega (H.W. Wilson), Readers' Guide Retrospective: 1890-1982 (H.W. Wilson), Regional Business News, Religion and Philosophy Collection, Science Reference Center, Short Story Index (H.W. Wilson), Social Sciences Full Text (H.W. Wilson), SocINDEX with Full Text, SPORTDiscus, Teacher Reference Center, Textile Technology Index, TOPICsearch, Urban Studies Abstracts, Vocational and Career Collection, Web News, Women's Studies International. 
Appendix B: Measurement Items of Self-Reported Stress Measure

Items adapted from Moore (2000) and Schaufeli et al. (1995):

- I felt strain due to the task demands.

- I felt emotionally drained from working on the memory task.

- I felt used up due to the task demands.

- I felt fatigued due to the task demands.

- I felt burned out from working on the memory task.

All items were on a 7-point likert-type scale ranging from strongly disagree to strongly agree. 


\section{About the Authors}

Stefan TAMS is an Assistant Professor of Information Systems at HEC Montréal, Canada. He received his PhD from the Department of Management at Clemson University. His research interests focus on the roles of aging, stress, and culture in technology-use behaviors, and on electronic commerce. His work has appeared or is scheduled to appear in several scientific journals, including Journal of Strategic Information Systems, Journal of the Association for Information Systems, and European Journal of Work and Organizational Psychology.

Kevin HILL is an Assistant Professor in the Department of Human Resources Management at HEC Montréal, Canada. He received his PhD from the Joseph L. Rotman School of Management at the University of Toronto. He conducts research primarily on the origins and effects of conflict in the workplace, and his papers have appeared, or are scheduled to appear, in the International Journal of Conflict Management, Journal of the Association for Information Systems, and Negotiation Journal.

Ana ORTIZ DE GUINEA is an associate professor of Information Systems at HEC Montréal. She holds a PhD in Information Systems from Queen's University, a MSc from the University of Lethbridge, and a degree in Computer Science and Engineering from the Universidad de Deusto. Prior to returning to academia, she worked as an information systems consultant. Her previous research has been published in many scientific journals, including Computers in Human Behavior, Information \& Management, Journal of Management Information Systems, and MIS Quarterly.

Jason THATCHER is a Professor of Information Systems at Clemson University. He also directs the Social Analytics Institute, an interdisciplinary center focused on understanding the implications of analytics for individual, organizational, and social issues. His research examines the influence of individual beliefs and characteristics on information technology use. He also studies strategic and human resource management issues related to the application of information technologies in organizations. His work appears in MIS Quarterly, Journal of Applied Psychology, and other outlets. His work has been supported by the National Science Foundation, National Parks Service, Salesforce.com, IBM, and other organizations. He lives in Greenville, SC, where he enjoys bonfires, barbecue and shag music on sultry summer nights.

Varun GROVER is the William S. Lee (Duke Energy) Distinguished Professor of Information Systems at Clemson University. He has published extensively in the information systems field, with over 200 publications in major refereed journals. Nine recent articles have ranked him among the top four researchers in the world based on number of publications in the top information systems journals, as well as citation impact (h-index>66). He is Senior Editor for MISQ Executive, and Senior Editor (Emeritus) for MIS Quarterly, the Journal of the AIS, and Database. He is currently working in the areas of IT value, dysfunctional aspects of IT, digital strategy and recently released his third book (with M. Lynne Markus) on process change. He is recipient of numerous awards from USC, Clemson, AIS, DSI, Anbar, PriceWaterhouse, and so on for his research and teaching. He is a Fellow of the Association for Information Systems. 